\title{
The Role Played by Blocking Systems over Europe in Abnormal Weather over Kingdom of Saudi Arabia in Summer 2010
}

\author{
Y. Y. Hafez and M. Almazroui \\ Department of Meteorology, Center of Excellence for Climate Change Research, King Abdulaziz University, \\ P.O. Box 80234, Jeddah 21589, Saudi Arabia \\ Correspondence should be addressed to Y.Y._Hafez; d_hafez@hotmail.com
}

Received 20 December 2012; Revised 13 February 2013; Accepted 13 February 2013

Academic Editor: Harry D. Kambezidis

Copyright (C) 2013 Y. Y. Hafez and M. Almazroui. This is an open access article distributed under the Creative Commons Attribution License, which permits unrestricted use, distribution, and reproduction in any medium, provided the original work is properly cited.

The present paper investigates the role played by blocking high systems over Europe in abnormal weather over the Kingdom of Saudi Arabia (KSA) in summer 2010. The NCEP/NCAR Reanalysis data of several meteorological elements such as surface air temperature, wind, sea level pressure, relative humidity, outgoing long wave radiation, precipitation rate, and geopotential height at level $500 \mathrm{hpa}$ ) for summer seasons for the period 1948-2012 and in particular of summer 2010 have been used and analyzed through the present work. Furthermore, the corresponding daily and monthly mean values of climatic indices NAO index, SOI, and El-Nino3.4 have been analyzed. The results uncovered that air current in the upper atmosphere over Europe and NAO, SOI and El-Nino3.4 have impacts on the weather conditions over KSA through the study period 1948-2012. During the period of persistence of blocking system over Europe in summer 2010, results revealed that; weather in KSA was fully controlled by two abnormal weather regimes. The first one is the European blocking system and negative anomaly of NAO from the north. The second one is the positive anomaly of SOI and negative anomaly of El-Nino3.4.

\section{Introduction}

In summer 2010, the heat wave hit Kingdom of Saudi Arabia (KSA) in June, setting an unofficial all-time temperature record. In June Jeddah, the second largest city in Saudi Arabia, recorded the extremely highest temperature of $52^{\circ} \mathrm{C}$ on 22 June 2010 [1]. Several parts of KSA lie under abnormal weather conditions and heat waves during that summer season. Whereas, temperature in KSA became more than its normal value by $1.5^{\circ} \mathrm{C}$. This temperature increase is more than twice the value of global warming temperature. Simultaneously, Europe was characterized by anomalously high temperatures due to a high-centered blocking over western Russia. The weather over Europe and Asia during July and August 2010 has been rather unusual [2, 3]. However, during that season, a blocking anticyclone over Europe dominated the weather pattern in Europe. During the blocking period, the position of the anticyclone favored a cold northerly airflow that ended the warm spell over Western Europe. At the same time, warm air from Africa reached Russia leading to a heat wave with temperatures rising to unprecedented levels. The weather over several countries in the northern hemisphere during the summer months, June, July, and August 2010, has been rather unusual [4].

It is found that La Nina induced low-level easterly anomalies over South and Southeast Asia led to an enhancement of the moisture transport to the North Arabian Sea and Pakistan during the summer 2010 season $[5,6]$. The summer temperatures in western Russia reached a record maximum since at least 1880 (National Oceanic and Atmospheric Administration) NOAA/National Climatic Data Center $(2010)[7,8]$ which even exceeded the extreme 2003 heat wave both in amplitude and spatial extent [9]. References [5,9] study the roles of European blocking and tropical-extratropical interaction in the 2010 Pakistan flooding. They found that the interaction between the tropical monsoon surges and the extratropical disturbances downstream of the European blocking was the key factor leading to the severe flooding in Pakistan.

However, blocking, in general, denotes the effect of a synoptic system acting as a barrier to the westerly flow splitting the jet stream [10]. The formation, persistence, and 
the role played by blocking systems in abnormal weather and climate in the northern hemisphere challenged in several scientific literatures (e.g., [11-17] and recently [18-21].

During the last several decades some, studies have applied subjective blocking criteria based on surface and mid troposphere observations of typical blocking flow configurations. Following the traditional [22] criterion, a blocking event can be identified through a split-flow regime in the middle troposphere as a double jet detectable over more than $45^{\circ}$ in longitude and persisting for more than 10 days. Since then, there have been modifications to the original [11] definition, demanding lower durations or extensions [23] as well as new restrictions on latitude location [24] to exclude semipermanent subtropical anticyclones. Recently, numerous criteria have been proposed in order to identify objectively atmospheric blocked flows. Most of them were based on zonal flow indices computed from meridional height gradients at the middle troposphere [25-28]. Other methodologies detected blocking events as positive height anomalies at the midtropospheric flow persisting for several days [29]. Moreover, the behavior of the North Hemisphere blocking has been traditionally described in terms of frequency, duration, and favored occurrence regions. Some authors have reported that blocking occurrence may be affected by North Hemisphere large-scale patterns such as the North Atlantic Oscillation (NAO) (e.g., [30, 31]. The relationship between blocking and the El Niño-Southern Oscillation (ENSO), however, has been widely studied [32,33]. Reference [21] studied the statistical relationships among the various $10^{\circ}-70^{\circ} \mathrm{E}$ midlatitude blocking anticyclone parameters and the weather of the Arabian Peninsula over a 40-year period (1968-2007) on seasonal, interannual, decadal, and long-term scales. They found that the Arabian Peninsula surface weather during the months of October, November, and December is affected more by the occurrence of midlatitude blocking anticyclones in the presence of El-Nino phase. For heat waves, [34], for the 2003 western European heat wave, found that human influences are estimated to have at least doubled the risk for such an extreme event. Other boundary forcing also contributed to the 2003 European heat wave including anomalous sea surface temperatures (SSTs) [35]. Reference [36] studied the 2010 Northern Hemisphere summer to explore whether early warning could have been provided through knowledge of natural and human-caused climate forcing. They used model simulations and observational data to determine the impact of observed sea surface temperatures (SSTs), sea ice conditions, and greenhouse gas concentrations. They found that analysis of forced model simulations indicates that neither human influences nor other slowly evolving ocean boundary conditions contributed substantially to the magnitude of this heat wave. Analysis of observations indicates that this heat wave was mainly due to internal atmospheric dynamical processes that produced and maintained a strong and longlived blocking event, and that a similar atmospheric pattern has occurred with prior heat waves in this region. They concluded that the intense 2010 Russian heat wave was mainly due to natural internal atmospheric variability.

In the summer of 2010, blocking highs over Europe significantly influenced climate events over large portions of the
Northern Hemisphere. The 2010 summer heat wave over western Russia was extraordinary, as the region experienced the warmest July (2010) since at least 1880, and numerous locations set all-time maximum temperature records. The heat waves in Russia that summer were extensively covered by the media in Europe and North America. Some scientists, associated with the IPCC 2007 Climate Change Documents [37], suggested that such heat waves were the result of the warming of the earth's climate due to human-added $\mathrm{CO}_{2}$. Heat waves could become more frequent in future [35]. This current condition in global mean surface temperature is thus consistent with prior conclusions of the IPCC Fourth Assessment Report that "warming of the climate system is unequivocal as is now evident from observations of increases in global average air and ocean temperatures, widespread melting of snow and ice, and rising global average sea level." The IPCC synthesis report goes on to state that "most of the observed increase in global average temperatures since the mid-20th century is very likely due to the observed increase in anthropogenic greenhouse gas concentrations." [20] has found that there is an outstanding climatic extreme record of SOI during July of summer 2010. In addition to that, there is a strong correlation between SOI and existing of wide extreme blocking over Europe through that season. In the present work, development and oscillation of the block over Europe each 10 days through the summer season of 2010 have been studied. An anomaly in geopotential height at a level of 500 hpa over Europe has been used to follow this block. As mentioned above, there are several criteria of blocking indexing.

This paper has four objectives. (i) To obtain the relationship between anomalies in geopotential height over Europe and abnormal weather over KSA through the period 19482012 of summer seasons. (ii) To obtain the effects of climatic indices (NAO, SOI, and El Nino3.4) on abnormal water over KSA summer seasons during the period 1948-2012. (iii) To uncover the role of blocking episode that persisted over Europe on the abnormal weather over KSA in summer 2010. (iv) In addition to that, the effects of climatic indices of weather over KSA through that summer season.

\section{Data and Methodology}

2.1. Data. The NCEP/NCAR Reanalysis project is using a state-of-the-art analysis/forecast system to perform data assimilation, within resolution of $2.5 \times 2.5$ degree lat/lon grid, using past data from 1948 to 2012. Data on the daily, monthly mean, and monthly time series of several meteorological elements surface air temperature, wind, sea level pressure, relative humidity, outgoing long wave radiation, precipitation rate, and geopotential height at level $500 \mathrm{hpa}$, and so forth over Kingdom of Saudi Arabia (KSA) for the summer seasons (months of June, July and August) have been obtained for the period 1948-2012 from the website http://www.esrl.noaa.gov/. The data have been provided by the NOAA/OAR/ESRL PSD, Boulder, Colorado, USA, and [38]. Furthermore, the corresponding daily and monthly mean values of NAO index, SOI, and El-Nino3.4 have 
been obtained from the Climate Prediction Centre website http://www.cpc.ncep.noaa.gov/.

In addition to that monthly data time series of geopotential height for summer season over Europe during the periods (1948 to 2012) have been used. However, unfortunately, the real observed station meteorological data for KSA are not homogenous enough for the present kind of study [39]. However, NCEP data set domain considered in the present work are extended to $30^{\circ} \mathrm{N}-70^{\circ} \mathrm{N}, 15^{\circ} \mathrm{W}-70^{\circ} \mathrm{E}$ for Europe and for KSA $12^{\circ} \mathrm{N}-32^{\circ} \mathrm{N}, 33^{\circ} \mathrm{E}-60^{\circ} \mathrm{E}$.

\subsection{Methodology}

2.2.1. Calculation of Monthly and Summer Season Averages. The averages calculation was done for each grid point in the domain $[17 \times 35$ degree lat/lon grids] and [13 $\times 24$ degree lat/lon grids] of the area of study, respectively for Europe and KSA regions. Monthly, summer and annual averages for meteorological elements (surface temperature, wind, mean sea level pressure, geopotential height, etc.) have been calculated using the NCEP/NCAR reanalysis daily and monthly data sets for summer season and statistical mean average (i.e., (June + July + August)/3) along the period 1948-2012. The summer composite mean comes from the statistical mean for three months from Jun to August, for the period of study. However, the interactive plotting and analysis NCEP/NCAR software program has been used for this analysis. The daily and summer season values of NAO index, SOI, and El-Nino3.4 have been calculated in the same manner. In fact, the ENSO phenomenon is the combination of SOI and El-Nino, [40].

2.2.2. Anomalies Methodology. The anomaly in the mean meteorological element, for example, surface air temperature (daily, weekly, and seasonal or annual) is $\left(A^{\prime}\right)$ for each grid point in the domain of study through the period of study 1948-2012 or any other selected period through the present work. This anomaly is calculated as the difference of the mean of (daily, weekly, and seasonal or annual) surface air temperature $(A)$ and its climatic mean value $(\overline{\dot{A}})$ for each grid point, whereas the climatic mean values for the surface air temperature have been taken through the period 1981-2010.

2.2.3. Local Significance and Calculation of Correlation Patterns. For given monthly and summer seasons resolved means of meteorological elements, for example, geopotential height at $500 \mathrm{hpa}$ level at each grid point is correlated with the climatic index (NAO, SOI, and El Nino3.4). Each grid point correlation is $t$-tested for local significance using [41] allowing for temporal autocorrelation according to [42] method. For field significance, the areal extent of locally significant correlations in a correlation map must exceed the areal extent that can be expected by chance. To estimate the correlation, we use the Monte-Carlo methodology. The fieldsignificance statistic is the area-weighted average absolute correlation of a given correlation map (considering only the locally significant correlations). The field-significance threshold is the 95th percentile of a 1000-member MonteCarlo population.

2.2.4. Linear Correlation Method. For a linear correlation analysis of the climatic indices NAO, SOI, and El-Nino3.4 datasets and the mean of meteorological elements, for example, surface air temperature over KSA during the study period 1948-2012, the methodology of Monte-Carlo has been used [42]. Based on this methodology, a correlation of \pm 0.3 would be significant. These significance levels are local for a resolution of $144 \times 73$ grid points (the resolution of the temperature dataset as an example). One would assume at least $0.05 \times(144 * 73)=526$ grids would be significant by chance at the one-sided $95 \%$ level (At website http://www.cdc.noaa.gov/Correlation/significance.html). In addition to that, linear correlation coefficient technique [43] has been used.

\section{Results}

3.1. Anomalies in Geopotential Height over Europe and Weather in KSA during Summer Seasons through the Period 1948-2012. To study the influence of blocking systems over Europe on the weather of KSA in summer 2010, it is convenient to study this effect through a long period first. This period is from 1948 to 2012. Through the present section, the NCEP/NCAR Reanalysis monthly data of geopotential height at $500 \mathrm{hpa}$ level over Europe from 1948 to 2012 will be used. In addition to that data on the daily monthly mean and monthly time series of several meteorological elements (surface air temperature, wind, sea level pressure, relative humidity, outgoing long wave radiation, precipitation rate, and geopotential height at level $500 \mathrm{hpa}$, etc.) over KSA for summer season (months of June, July, and August) have been used. Daily and monthly mean values of NAO index, SOI, and El-Nino3.4 have been obtained for the same period.

From time series analysis of NCEP/NCAR monthly data of anomaly of geopotential height at $500 \mathrm{hpa}$ level over Europe during the summer seasons for the period 1948-2012 is revealed the following.

(1) Analysis of June months geopotential height through the period 1948-2012 shows that the anomaly values of geopotential height over Europe varies from year to year within the minimum value $(-43 \mathrm{~m})$ in the year 1962. Meanwhile, the maximum value is $+36 \mathrm{~m}$ in 2006, with a positive trend through the period of study, see Figure 1(a).

(2) For July months, geopotential height analysis revealed that the anomaly values of geopotential height varies with a distinct positive trend with the lowest value being $-50 \mathrm{~m}$ in 1965 . The outstanding highest value is $+32 \mathrm{~m}$ in July of 2010, see Figure 1(b).

(3) For August month's dataset, through the period 19482012, also, there is a positive trend of variation of anomaly of geopotential height over Europe, with two minima about $-38 \mathrm{~m}$ in the years 1963,1966 and two 
maxima about $+20 \mathrm{~m}$ for the years 2006 and 2010 , see Figure 1(c).

(4) Approximately, the variation of anomaly of geopotential height of summer seasons through the period 1948-2012 is a typical variation of it in August months; see Figure $1(\mathrm{~d})$.

(5) It is notable that the trends for the four above mentioned figures approximately have the same positive trend character starting from year 2000 and remain over the normal values through the period 20002012.

3.2. Anomalies in Weather Elements over KSA in Summer Seasons through the Period 1948-2012. From time series linear trend analysis for NCEP/NCAR monthly data of anomaly of weather meteorological elements over KSA, for the above mentioned weather elements, the summer seasons during the period 1948-2012 the following is becoming clear.

(1) Variabilities of the anomalies in mean surface air temperature over KSA through the summer months (June, July, and August) and the summer seasons through the period 1948-2012 have the same trends with positive trend. Approximately, there are positive anomalies in surface temperature for the period 2000-2012 for all summer months and for the summer seasons, see Figure 2(a).

(2) Anomaly in geopotential height over KSA changes dramatically toward positive trends for months and summer seasons through the period of study. The trends of geopotential height are more than the normal values for June and August months and summer seasons through the period 2000-2012. Meanwhile, it is started more than normal values for the period 2008-2012 for July months, see Figure 2(a).

(3) The analysis of anomaly of Gauss zonal momentum flux at the surface revealed that there are very few positive trends through the period of study for months and seasons of summer. These trends became more than the normal values for the period 2000-2012, see Figure 2(c).

(4) The analysis of anomaly of Gauss meridional momentum flux at the surface shows that there are few negative trends through the period of study for months and seasons of summer. The trends became less than the normal values for the period 1996-2012 for the summer months, see Figure 2(d).

(5) Time series analysis of anomalous mean sea level pressure shows that there are positive trends for months and seasons of summer of the period of study, whereas these trends are more than the normal values for the months of July for the period 19922012. In addition to that, mean sea level pressure values are more than its normal for June, August, and summer seasons starting from 2000 till 2012 years, see Figure 2(e).
(6) Variability of the anomaly in surface relative humidity over KSA through the summer months and the summer seasons through the period 1948-2012 has the same trend with negative trend. Exactly, there is a negative anomaly in surface relative humidity for the period 2000-2012 for all summer months and for the summer seasons too. In addition to that, it is the same situation there is a negative trend for precipitation rate. See Figures 2(f) and 2(g).

(7) Variabilities of the anomalies in the top atmosphere outgoing long wave radiation over KSA during the summer months of the period 1948-2012 have the same trends with positive trend direction. Obviously, there are positive anomalies in outgoing long wave radiation for the period 2000-2012 for all summer months and for the summer seasons, see Figure $2(\mathrm{~h})$.

\subsection{Correlation between Anomalies in Weather Elements} over KSA and Climatic Indices (NAO, SOI, and El Nino3.4) in Summer Seasons in the Period 1948-2012. Correlation coefficient analysis between the principal weather elements (geopotential height, surface air temperature, .995 sigma stream function, and precipitation) over KSA and climatic indices (NAO, SOI and El Nino3.4) in summer seasons in the period (1948-2012) has been studied. The results revealed the following.

(1) There is a very weak correlation arranged ( -0.2 and +0.1 ) between geopotential height over KSA and NAO through the period of study, see Figure 3(a). Meanwhile, it is found that there is a relatively significant negative correlation coefficient $(-0.4)$ between the surface air temperature over KSA and NAO, see Figure 3(b). Again, there is a weak negative correlation coefficient around -0.2 between the sigma stream function over KSA and NAO in summer seasons during the study period, see Figure 3(c). It is found that precipitation rate over KSA is correlated with the NAO with relatively significant positive correlation coefficient $(+0.4)$ through the available data period (1979-2011) as shown in Figure 3(d).

(2) It is a relatively significant negative correlation coefficient of -0.3 between geopotential height over KSA and SOI through the period of study, as shown in Figure 4(a). Meanwhile, it is found that there is a correlation coefficient arranged $(-0.2$ and +0.2$)$ between the surface air temperature over KSA and SOI, see Figure 4(b). It is found that there is a weak positive correlation coefficient $(+0.2)$ between the sigma stream function over KSA and SOI in summer seasons during the study period, see Figure 4(c). It is noticed that the precipitation rate over $\mathrm{KSA}$ is correlated with SOI with notably significant negative correlation coefficient $(-0.4)$ through the data period 1979-2011, as shown in Figure 4(d).

(3) there is notably significant positive correlation coefficient of +0.5 between geopotential height over KSA 


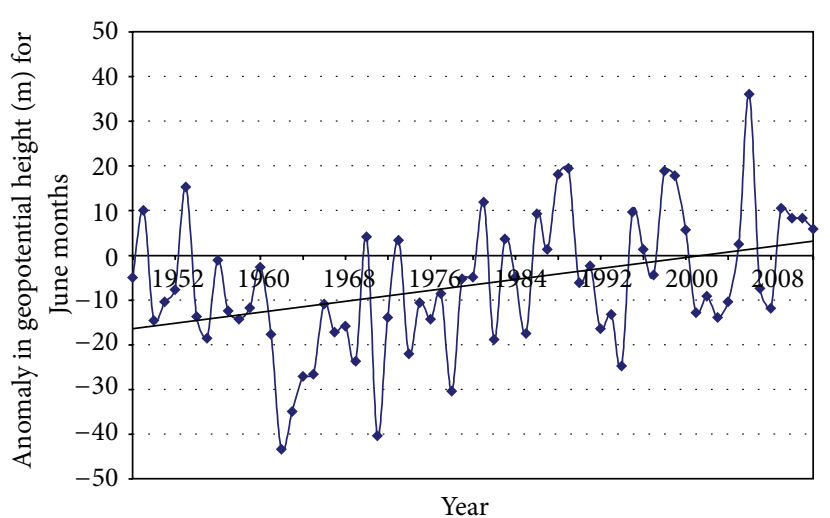

(a)

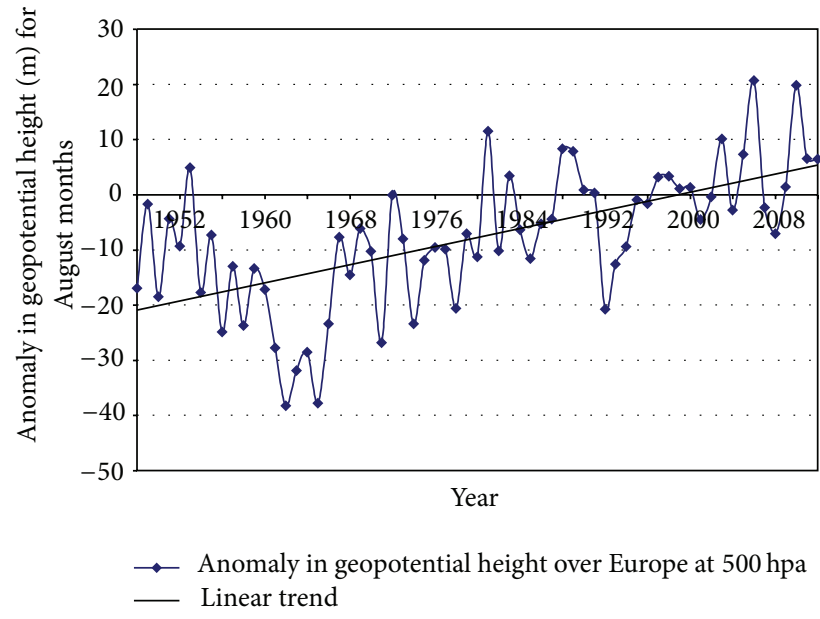

(c)

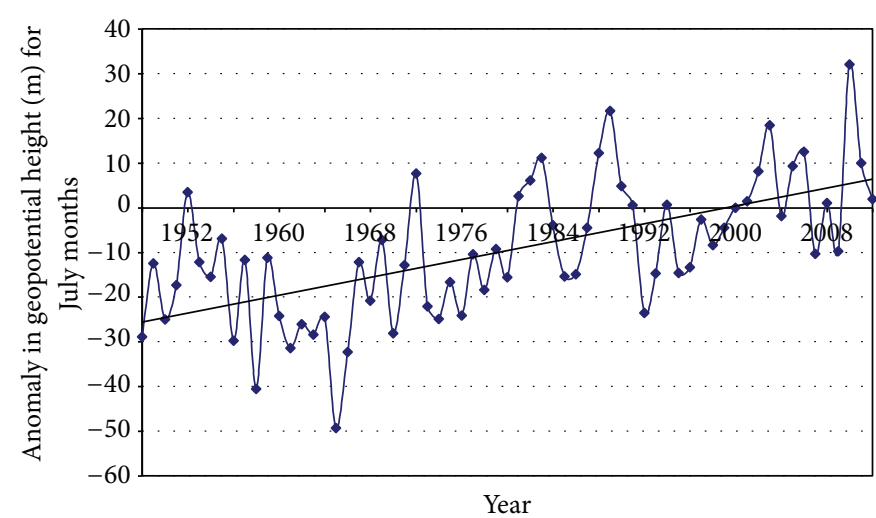

(b)

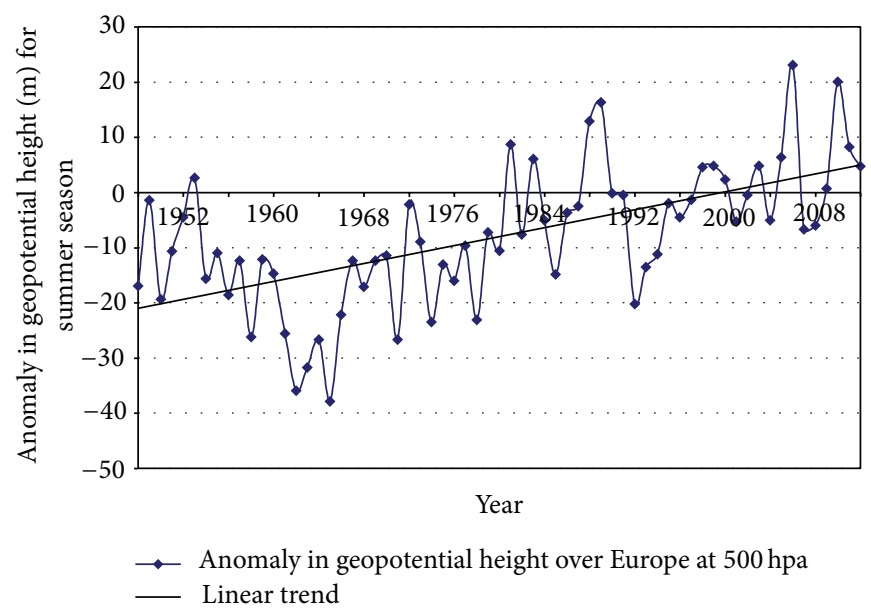

(d)

Figure 1: Time series of geopotential anomalies (m) at 500 hpa level over Europe through summer seasons of the period 1948-2012. (a) June months, (b) July months, (c) August months, and (d) summer seasons.

and El Nino3.4 through the study period, as shown in Figure 5(a). Meanwhile, it is found that there is a very weak correlation coefficient about -0.1 between the surface air temperature over KSA and El Nino3.4, as it is clear from Figure 5(b). It is clear that there is a very weak correlation coefficient arranged $(-0.2$ to +0.1$)$ between the sigma stream function over KSA and SOI in summer seasons during the period of study, as shown in Figure 5(c). It appears that the precipitation rate over KSA is correlated with El Nino3.4 with positive correlation coefficient $(+0.3)$ through the period 1979-2011, as shown in Figure 5(d).

3.4. Blocking System over Europe in Summer 2010. Through the present work, the synoptic and numeric criteria of the formation of blocking systems over, Northern Hemisphere according to $[11,22,44]$ had been used to identify and to follow the daily persistence of the blocking systems. These criteria have basic conditions like the westerly air current a loft must split into two distinct branches, this splitting must be Northern latitude of $30^{\circ} \mathrm{N}$, the anomalies in geopotential height values at $500 \mathrm{hpa}$ must be more than $+100 \mathrm{~m}$ for blocking high pressure system, and these conditions must persist 10 days or more. Applying this criteria in the present study, analysis of a 10-day anomaly composite mean of geopotential height at level $500 \mathrm{hpa}$ over Europe revealed that Europe lies under the influence of blocking system all the 92 days during the period of study (92 days of summer season 2010). This block oscillated over Europe and became more dominant over Eastern Europe almost of the persistence days However, this blocking system developed over western Russia. This blocking episode over the Northern Hemisphere and mainly over Russia persisted all the summer season of year 2010. There exist positive anomalies more than $+100 \mathrm{~m}$ in geopotential height over Europe through that season. This block episode oscillates over Europe through its duration time and persisted over Russia. Anomaly in geopotential height varies from June to August. The maximum anomaly of $+220 \mathrm{~m}$ existed in August. Meanwhile, the minimum positive anomaly occurred in the initiation and dissipation days of this blocking episode, as illustrated in Figure 6 (from 6(a) to $6(i))$ that shows a 10 day composite anomaly in geopotential height field at level $500 \mathrm{hpa}$ over Europe during summer 2010. It appears that there is a unique summer geopotential 


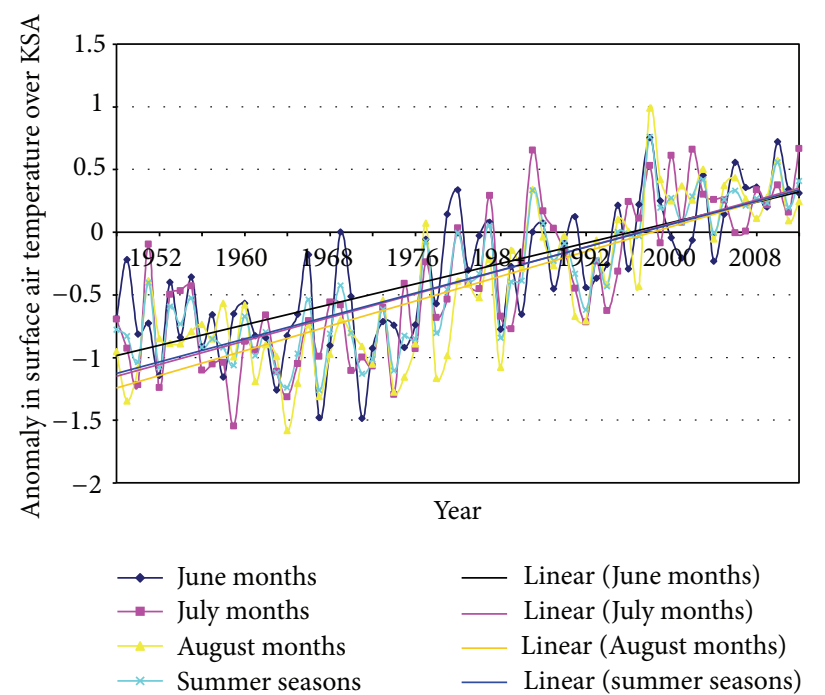

(a)

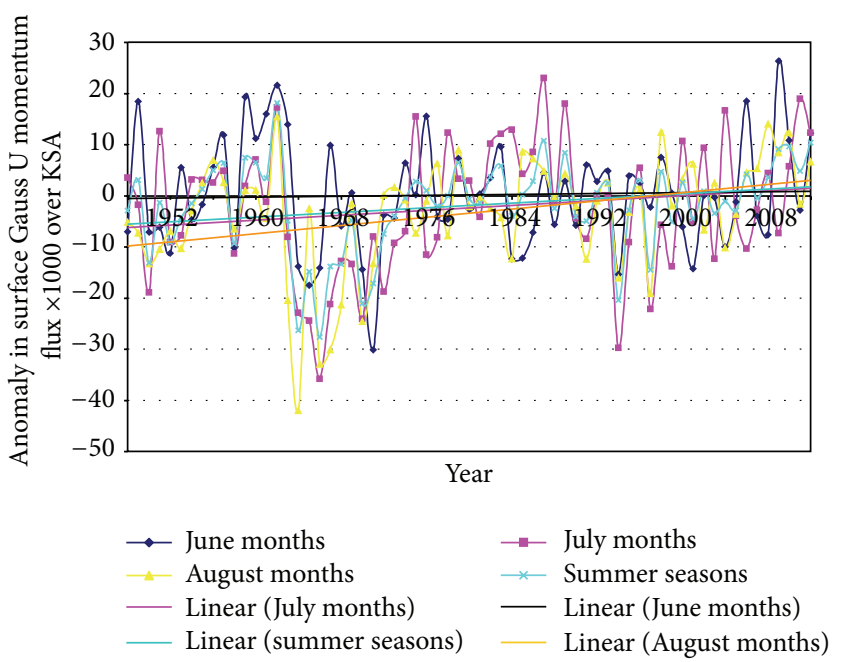

(c)

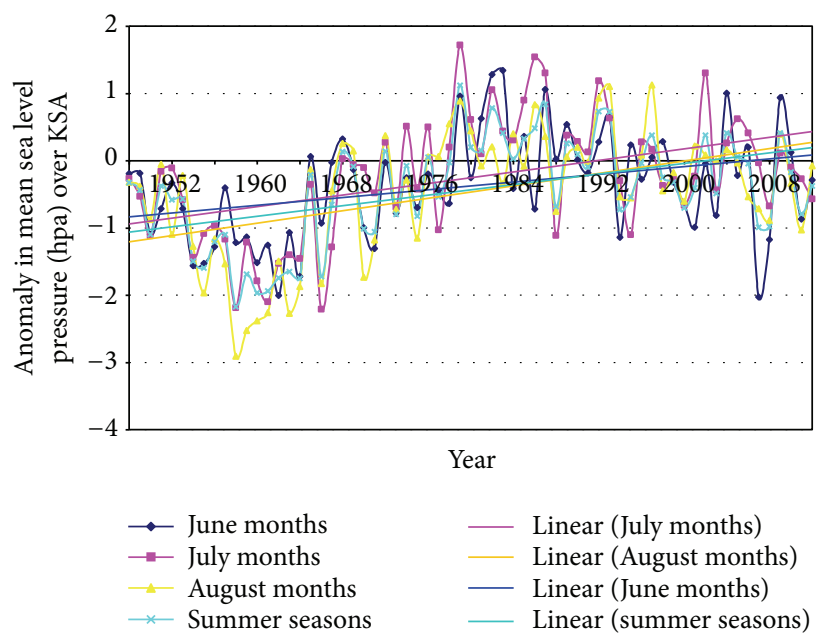

(e)

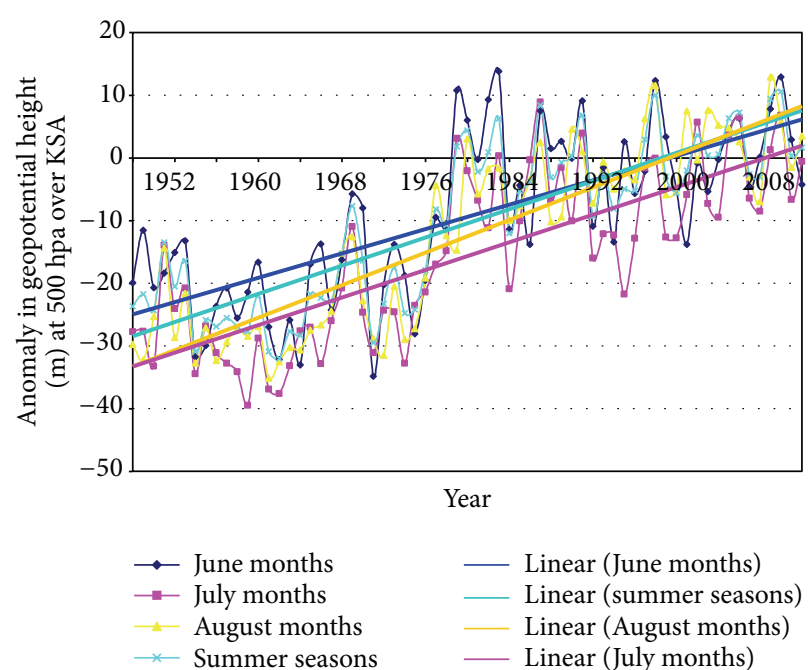

(b)

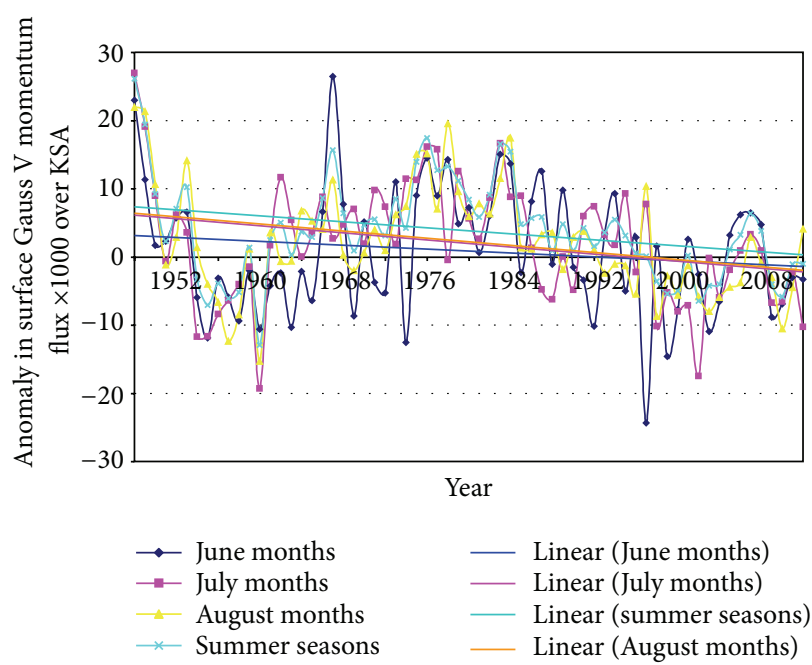

(d)

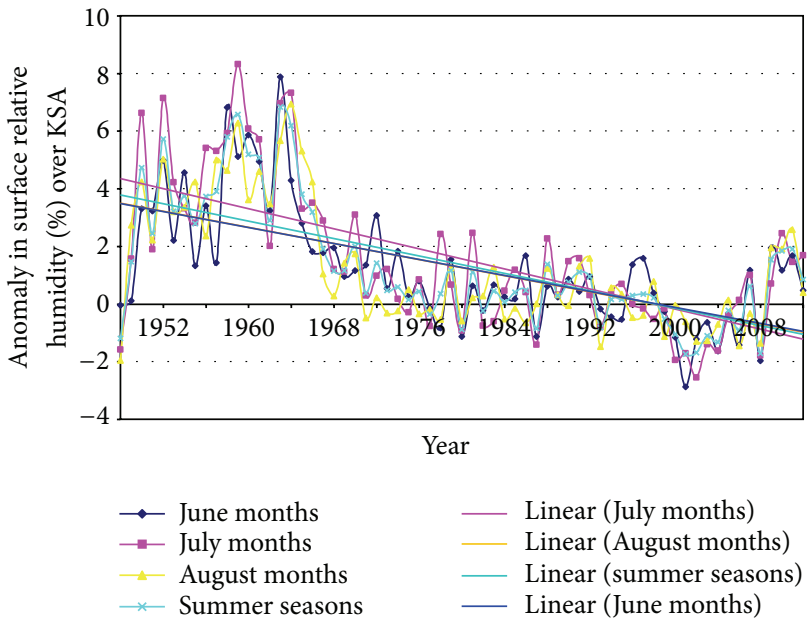

(f)

FIgure 2: Continued. 


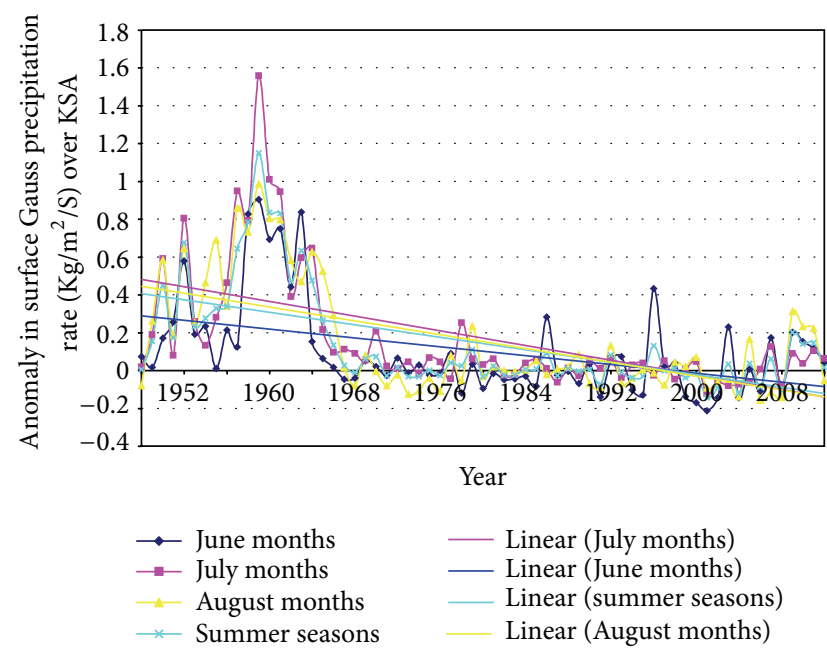

(g)

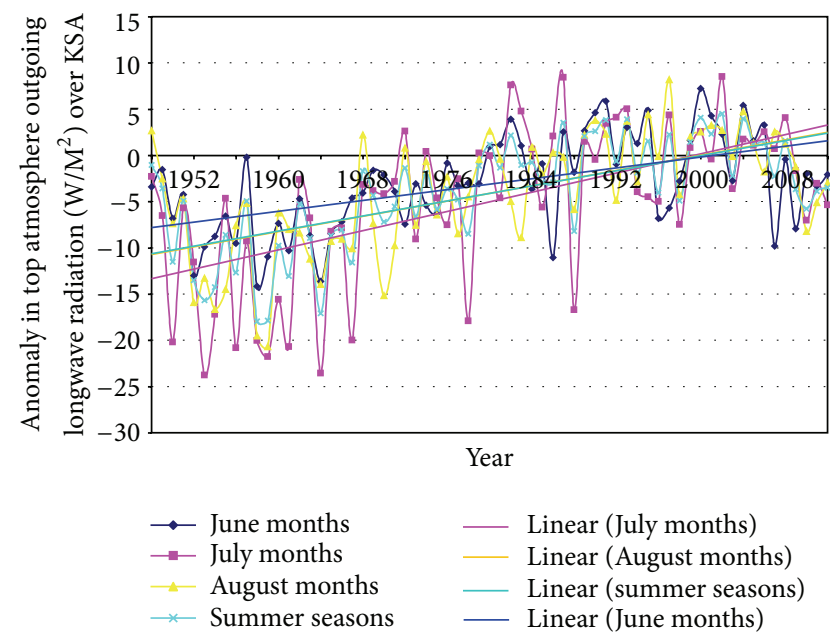

(h)

FIGURE 2: The time series and the linear trend for anomaly of weather meteorological elements over KSA through the period 1948-2012.

height distribution over Europe in summer season 2010, see Figure 6(j).

3.5. The Role Played by Blocking System over Europe and Abnormal Weather over KSA in Summer 2010. From the above mentioned study, weather over Europe became under full control of blocking system through summer seasons, whereas the existing of a blocking episode must be accompanied with abnormal weather. Analysis of anomaly in geopotential height at $500 \mathrm{hpa}$ level indicates the occurrence of the blocking episode. The relationship between the anomaly in geopotential height at 500 hpa level over Europe in summer 2010 and abnormal weather over KSA through that season has been studied. For the purpose of this study, weekly mean of data over Europe and KSA during the period 1 June-30 August of summer 2010 have been analyzed using anomaly method and linear correlation coefficient technique. The results revealed that, there is positive anomaly in geopotential height over Europe and KSA through the period of study, although the trend is on opposite sides. The slope of these two trends is not sharp see Figure 7(a). The variability of surface air temperature over KSA is matched to the geopotential height at $500 \mathrm{wpa}$ level over Europe, whereas there is a positive typical trend for them through the study period as shown in Figure 7(b). There is contradicting relationship variability between geopotential height over Europe and the mean sea level pressure over KSA; the trends are completely in the opposite direction, as is clear in Figure 7(c). The response of surface wind variability over KSA is not clear to the variability of geopotential height over Europe through this blocking system see Figure $7(\mathrm{~d})$. The surface zonal wind over KSA is completely westerly and affected by geopotential height over Europe through the period of study as shown in Figure $7(\mathrm{e})$. Surface meridional wind has a dramatic variability between north and south and contradicting with the geopotential height variability over Europe, as shown in Figure 7(f). For outgoing long wave radiation over KSA, it is clear that it is oscillating sharply between positive and negative anomalies through the study period with a positive trend, and its relation with geopotential height variability over Europe is not clear as shown in Figure 7(g). Precipitation rate has a positive trend through the study period and its variation is opposite to the geopotential height variation over Europe through this block episode, see Figure 7(h). Surface relative humidity over KSA has a sharp positive trend and has varied weakly contradicting to the geopotential height over Europe through the study period, as shown in Figure 7(i). It is clear that anomaly in stream function over KSA has a negative trend and is affected reversely by the geopotential height over Europe, as it is clear in Figure $7(\mathrm{j})$. The result of correlation coefficient analysis between the above meteorological elements and blocking over Europe (as reprinted by anomaly in geopotential height at $500 \mathrm{hpa}$ level over Europe) shows that there exist only significant correlation coefficients $[+0.34,+0.30$, and -0.45$]$ between the wind speed, surface zonal, and precipitation rate over KSA and the blocking over Europe, respectively.

\subsection{The Relationship between Climatic Indices NAO Index, SOI, and El-Nino3.4 and Abnormal Weather over KSA in Summer 2010}

3.6.1. The Relationship between Climatic Indices NAO Index and Abnormal Weather over KSA. The relationship between the climatic indices NAO index, SOI, and El-Nino3.4 and abnormal weather over KSA in summer 2010 has been studied using anomaly method and linear correlation coefficient technique analysis. The time series analysis of weekly data of weather elements over KSA and the above-mentioned climatic indices was analyzed. The results revealed that for most of the period of summer 2010, NAO index has a negative sign and has slight negative trend. Geopotential height at level 500 hpa over KSA trend is matched with NAO index 


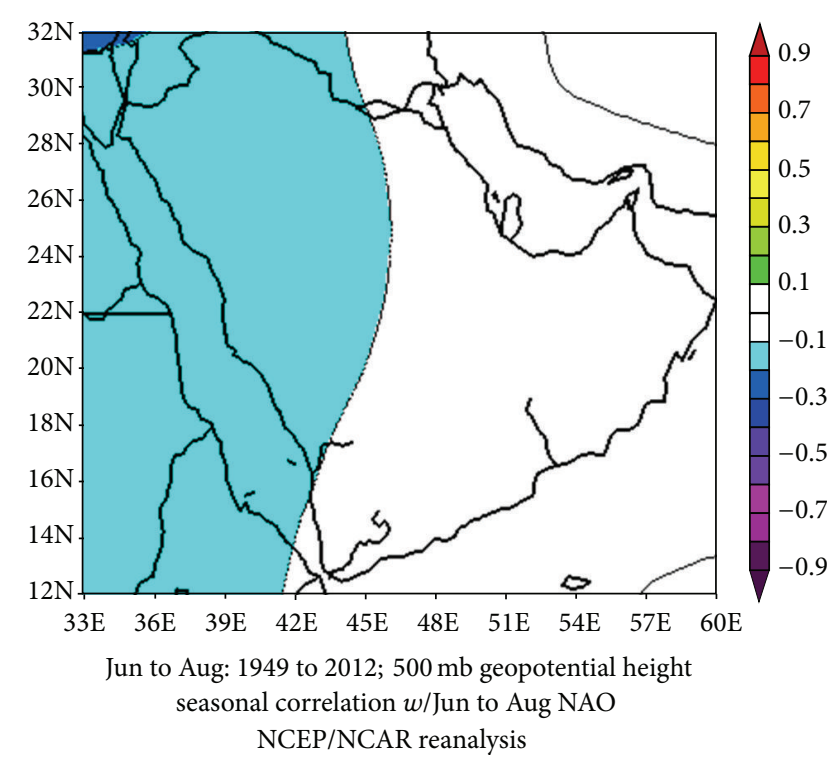

(a)

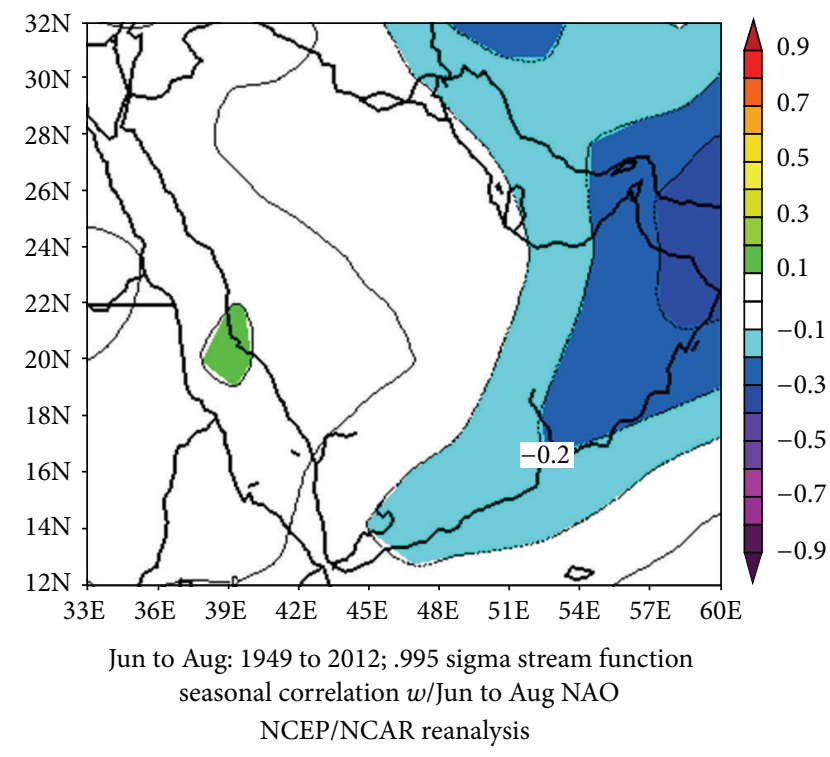

(c)

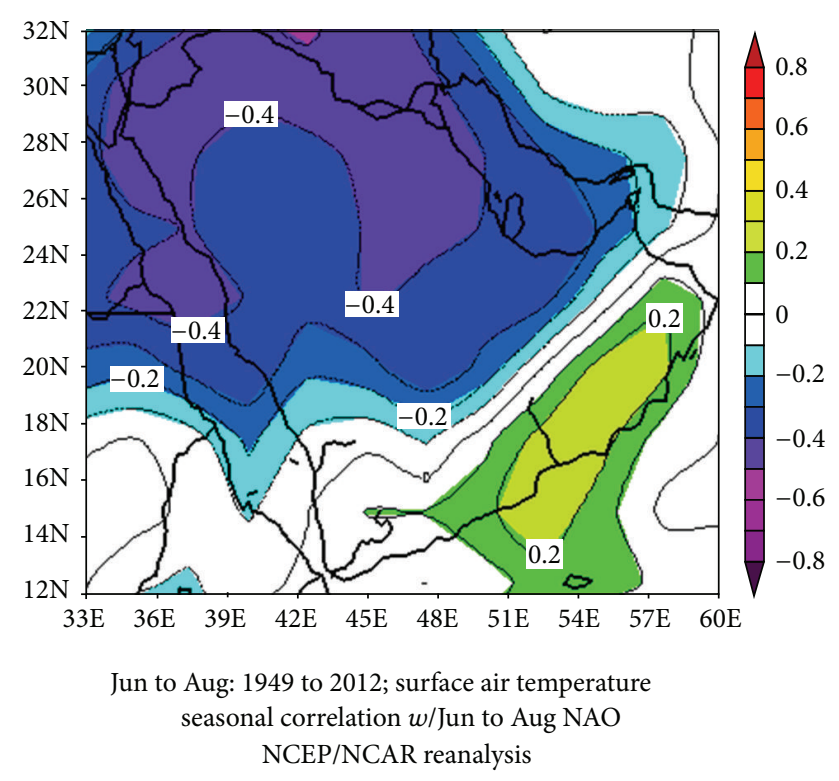

(b)

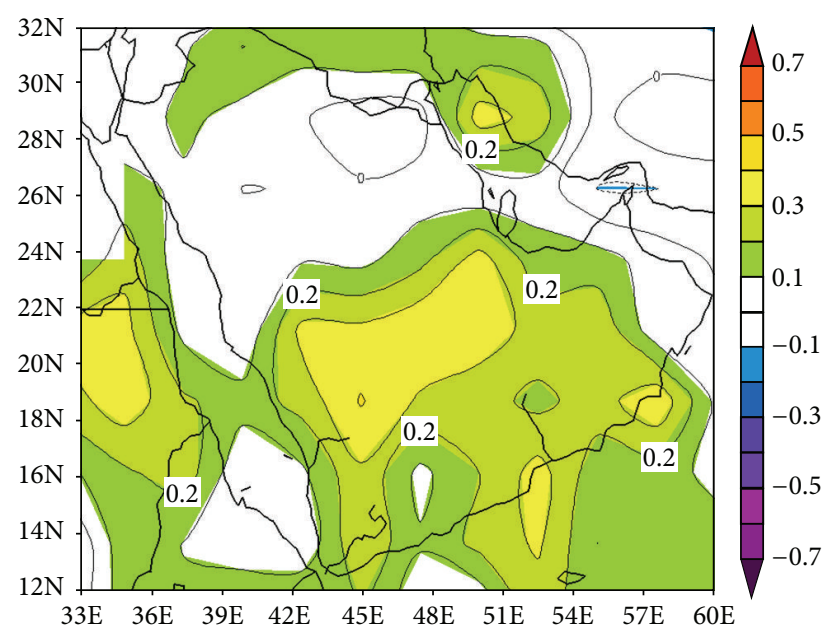

Jun to Aug: 1979 to 2011; surface CMAP precipitation (enhanced) seasonal correlation $w /$ Jun to Aug NAO CMAP-enhanced precipitation

(d)

FIGURE 3: The distribution of the linear correlation coefficient between weather elements over KSA and NAO through the period of study.

trend through the study period, see Figure 8(a). Surface air temperature has a positive trend against the negative NAO trend, see Figure 8(b). There is a negative trend of mean sea level pressure mentioned with NAO index trend, as shown in Figure 8(c). Approximately, the wind speed varies very slowly through the time period of the block episode with fixed trend, see Figure $8(\mathrm{~d})$. Also, the surface zonal wind varies with little positive trend; meanwhile, NAO has a negative one as shown in Figure 8(e). Meridional wind over KSA varies with opposite direction trend with NAO through the study period as it is clear in Figure 8(f). The outgoing long wave radiation over KSA varies completely contradicting NAO values. Figure $8(\mathrm{~g})$ shows it clearly. Trends of precipitation rate and surface relative humidity had an opposite direction rather than that of NAO through the study period, see Figures (8(h), and $8(\mathrm{i}))$. Stream function over KSA varies, completely influenced by NAO through that period. The result of correlation coefficient analysis between the above mentioned meteorological elements and NAO shows that there only exists a significant negative correlation coefficient $[-0.63$ and -0.66$]$ between the outgoing long wave radiation and precipitation rate over KSA and NAO, respectively.

3.6.2. The Relationship between SOI and Abnormal Weather over KSA in Summer 2010l. The relationship between the SOI and abnormal weather over KSA in summer 2010 has been 


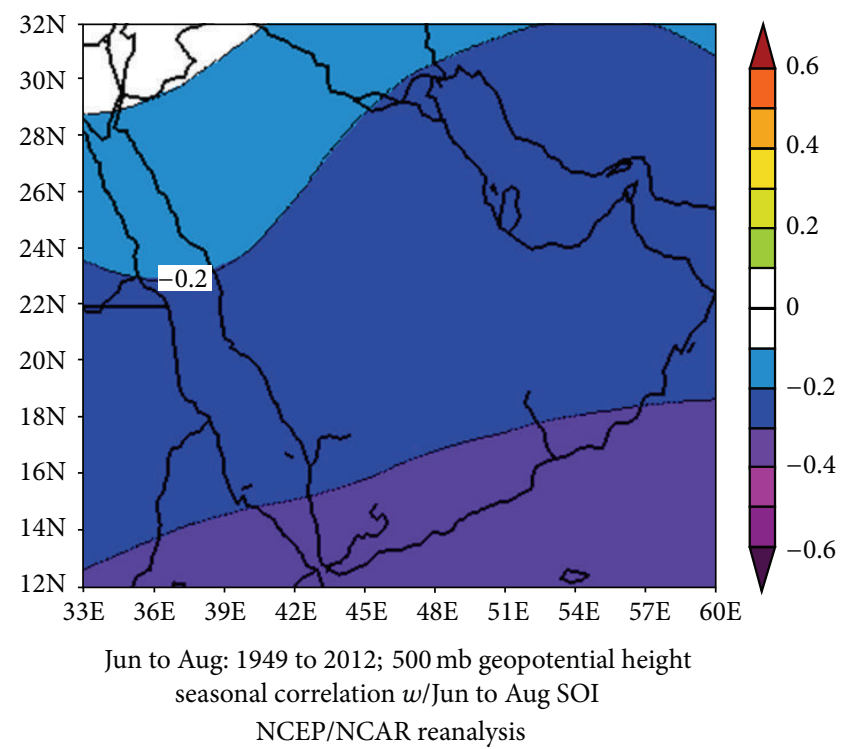

(a)

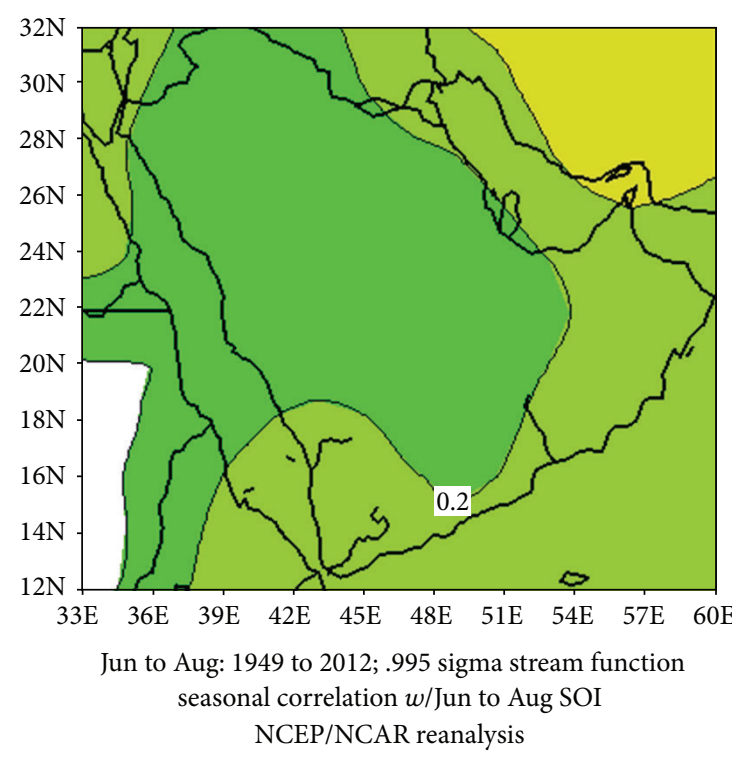

(c)

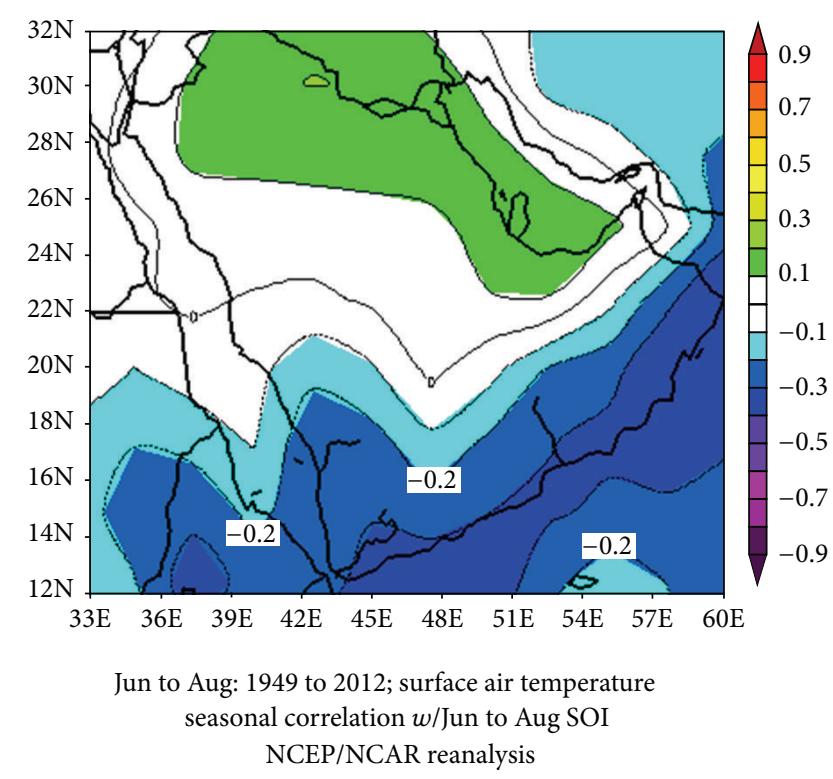

(b)

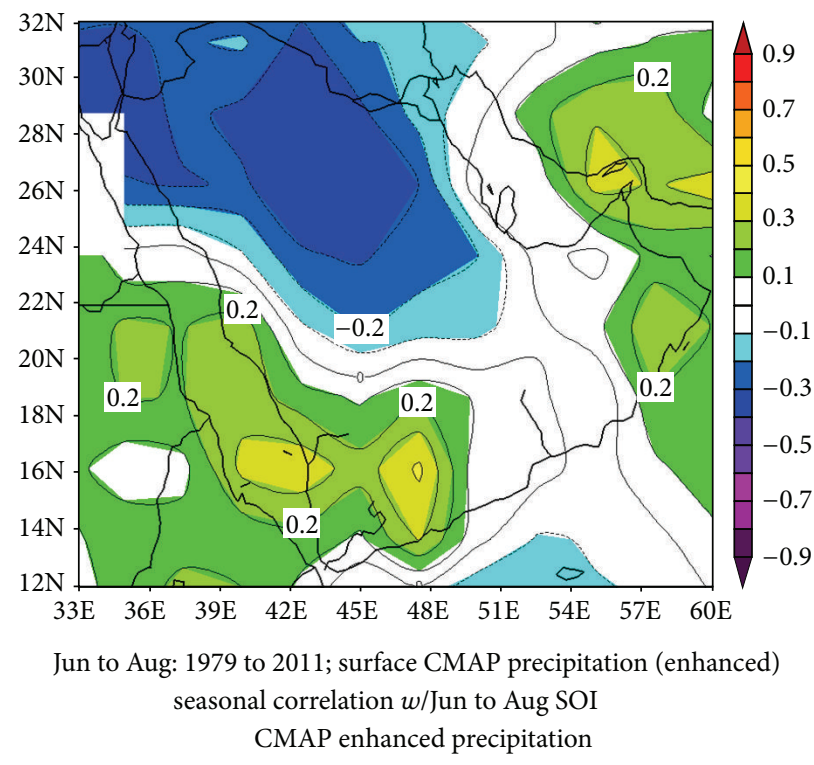

(d)

FIGURE 4: The distribution of linear correlation coefficient between weather elements over KSA and SOI through the period of study.

studied. The time series analysis of weekly data of weather elements over KSA and SOI was analyzed using anomaly methodology. The results uncovered that for most of the period of summer 2010, SOI has a positive anomaly value and has an outstanding positive trend. Geopotential height at level 500 hpa over KSA has a negative trend through the study period, see Figure 9(a). The surface air temperature over KSA and SOI has the same positive trend, as it is clear in Figure 9(b). There is a negative trend of mean sea level pressure mentioned with opposite trend of SOI, as it is clear in Figure 9(c). Approximately, the surface wind speed is nearly constant through the time period of the block episode with the fixed trend without a clear variation with SOI see
Figure 9(d). Meanwhile, the surface zonal and meridional wind varies with a positive trend and as the same trend of SOI, see Figures (9(e) and 9(f)). For the outgoing long wave radiation over KSA it is clear that it varies follow completely the SOI variation. Figure $9(\mathrm{~g})$ shows it clearly. Trends of precipitation rate and surface relative humidity had the same positive direction with SOI trend through the study period, see Figures (9(h), and 9(i)). The stream function varies completely following the variation of ElNino3.4 with the same negative trend as shown in Figure 9(j). The result of correlation coefficient analysis between the above mentioned meteorological elements and SOI revealed that there is only a significant positive correlation coefficient 


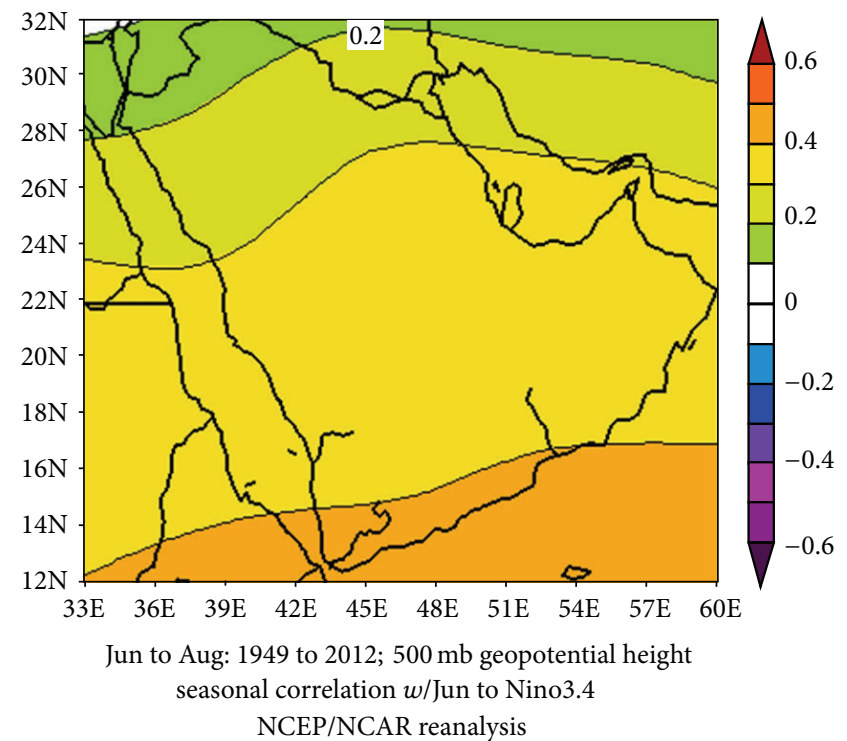

(a)

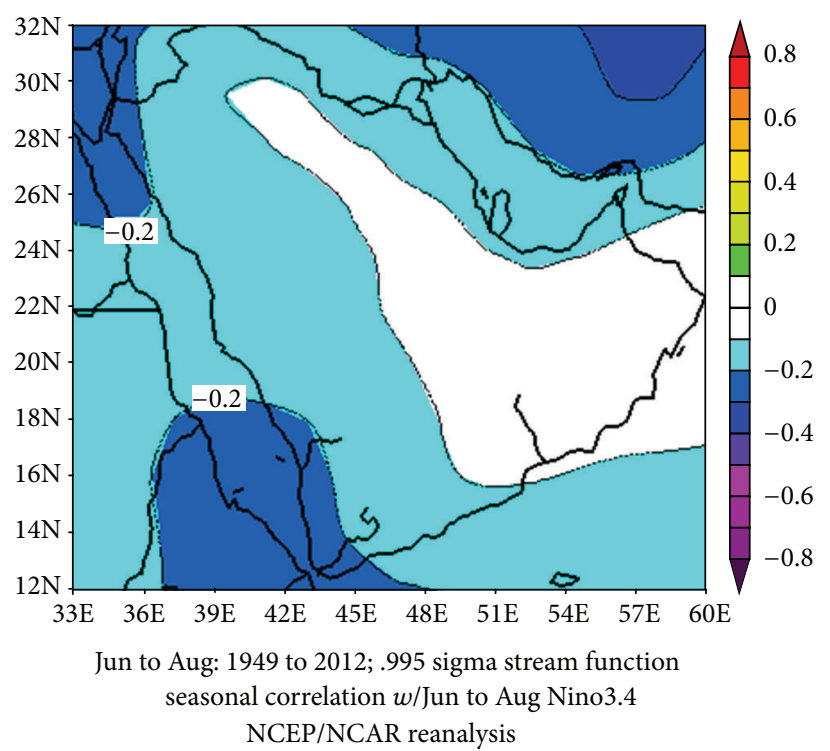

(c)

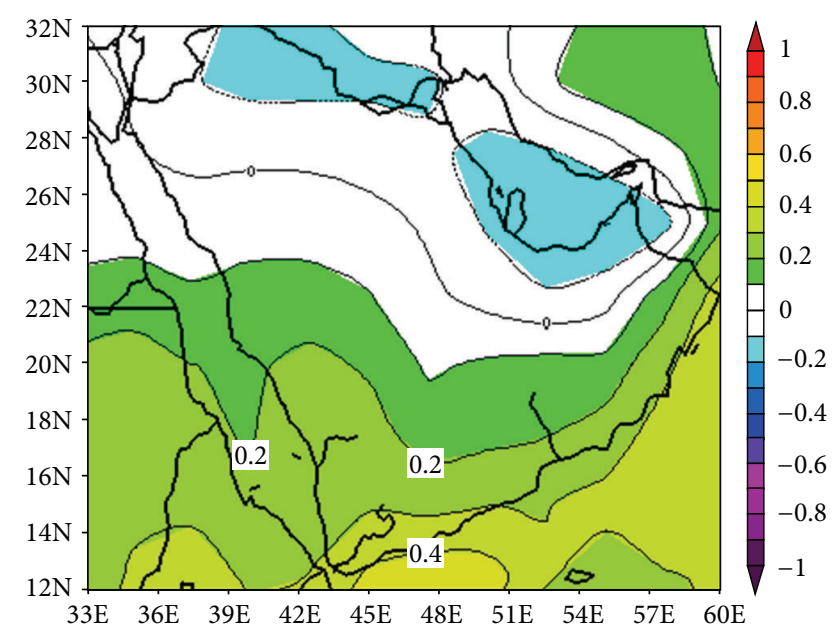

Jun to Aug: 1949 to 2012; surface air temperature seasonal correlation $w /$ Jun to Aug Nino3.4 NCEP/NCAR reanalysis

(b)

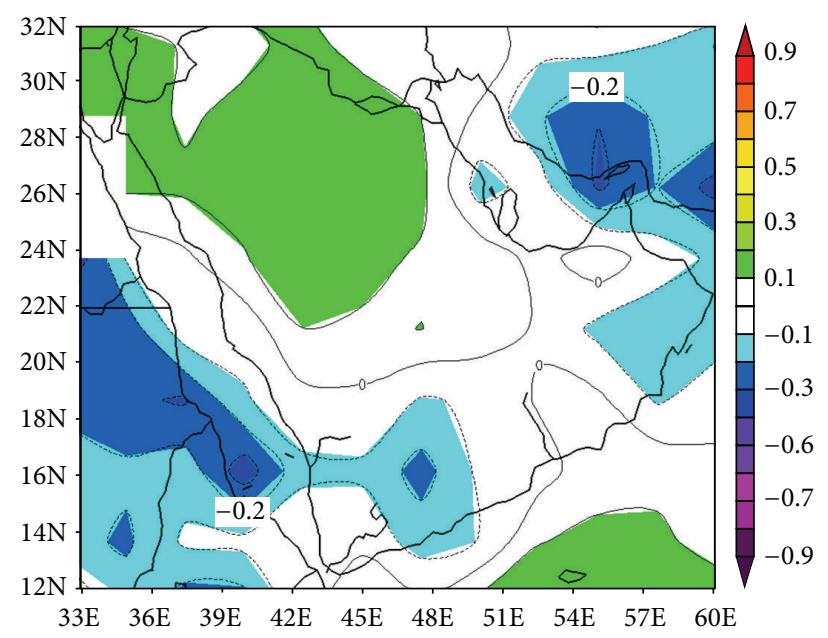

Jun to Aug: 1979 to 2011; surface CMAP precipitation (enhanced) seasonal correlation $w /$ Jun to Aug Nino3.4 CMAP enhanced precipitation

(d)

FIGURE 5: The distribution of linear correlation coefficient between weather elements over KSA and El-Nino3.4 through the period of study.

$[+0.38,+0.39,+0.33$ and +0.45$]$ between the surface wind speed, outgoing long wave radiation, precipitation rate, and relative humidity over KSA and SOI, respectively.

\subsubsection{The Relationship between Climatic Index El-Nino3.4 and} Abnormal Weather over KSA in Summer 2010. The relationship between the climatic index El-Nino3.4 and abnormal weather over KSA in summer 2010 has been studied. The time series analysis of weekly data of weather elements over KSA and El-Nino3.4 was analyzed using anomaly methodology. The results revealed that through the period of summer 2010, El-Nino3.4 has a negative anomaly with a distinct negative trend. Surface air temperature and geopotential height at level
500 hpa over KSA had a positive trend through the study period (see Figures 10(a) and 10(b)). The mean sea level pressure over KSA varies completely following the variation of El-Nino3.4

with the same negative trend as shown in Figure 10(c). Approximately, the wind speed varies very slowly through the time period of the block episode with fixed trend, see Figure 10(d). Surface zonal and meridional wind varies completely following the variation of El-Nino3.4 with the same negative trend as it is clear in Figures (10(e) and 10(f)). The outgoing long wave radiation over KSA varies, completely contradicting El-Nino3.4 values as appearing in Figure 10(g). Trends of precipitation rate and surface relative humidity 

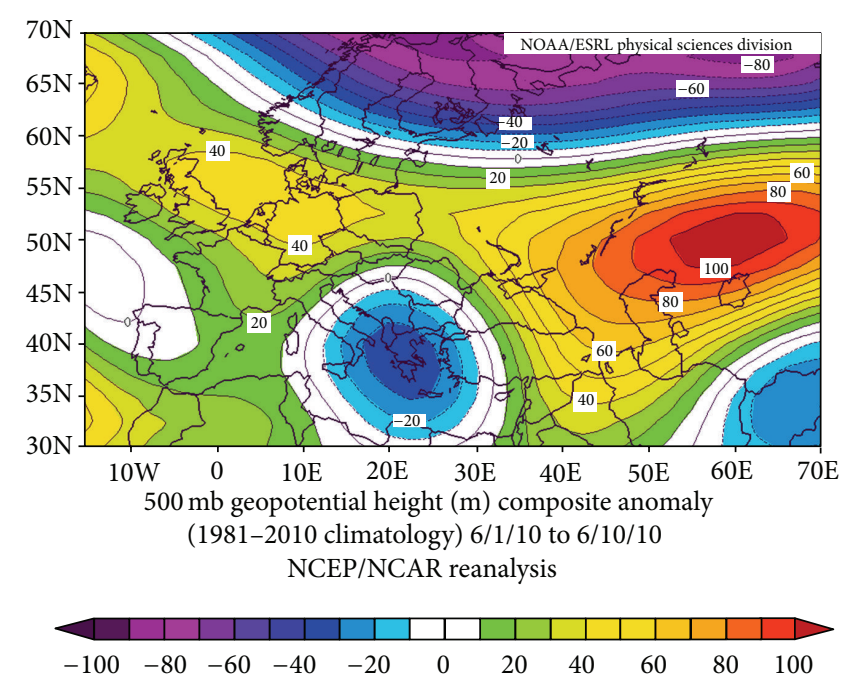

(a)

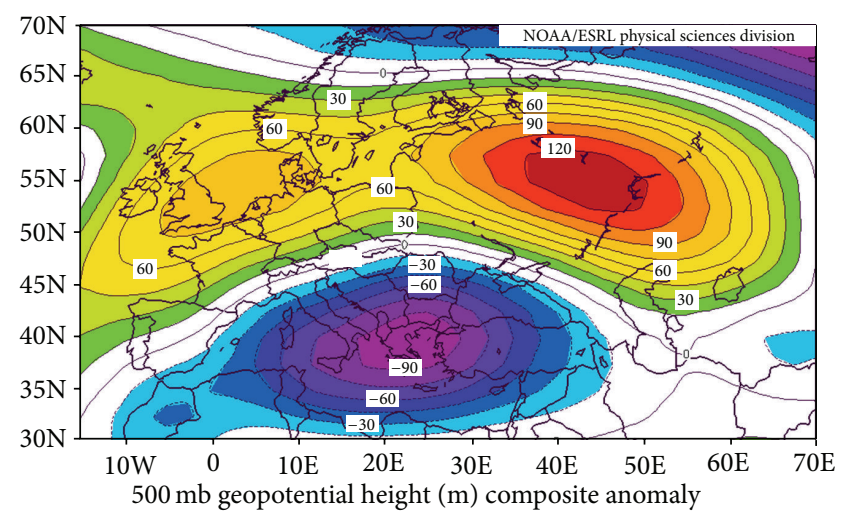
(1981-2010 climatology) 6/21/10 to $6 / 30 / 10$ NCEP/NCAR reanalysis

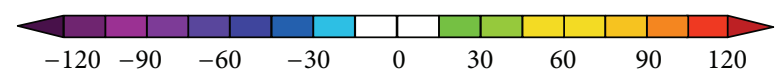

(c)

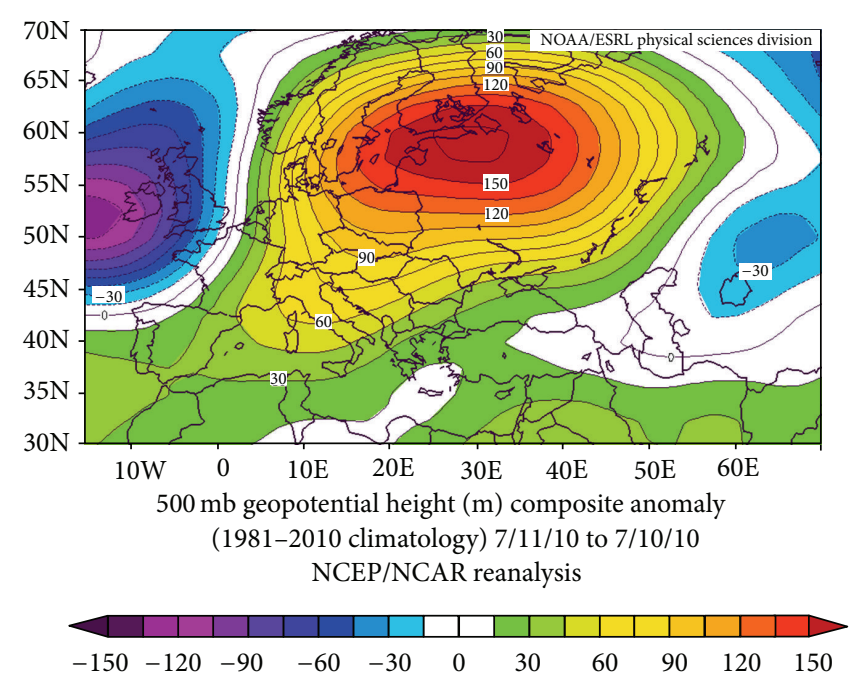

(e)
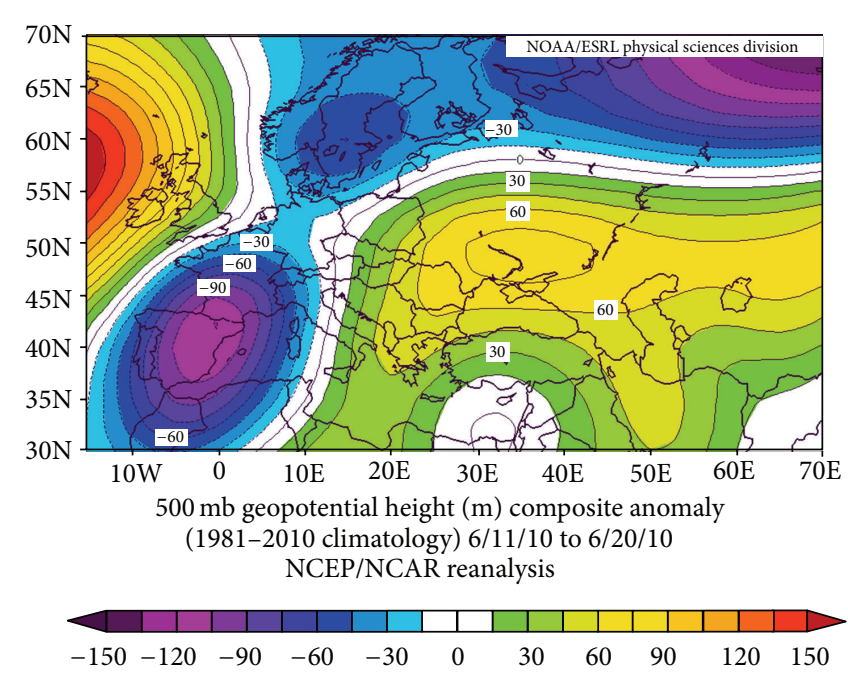

(b)

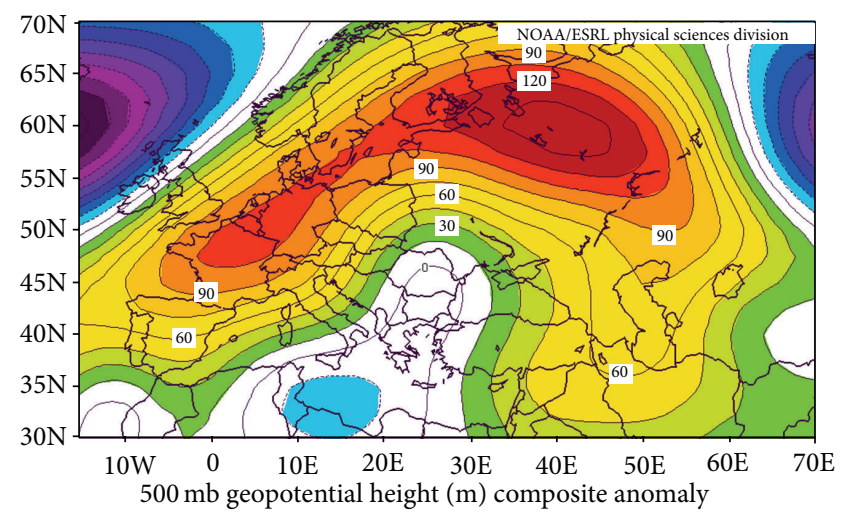
(1981-2010 climatology) 7/1/10 to $7 / 10 / 10$ NCEP/NCAR reanalysis

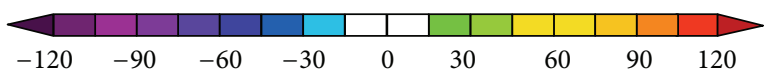

(d)

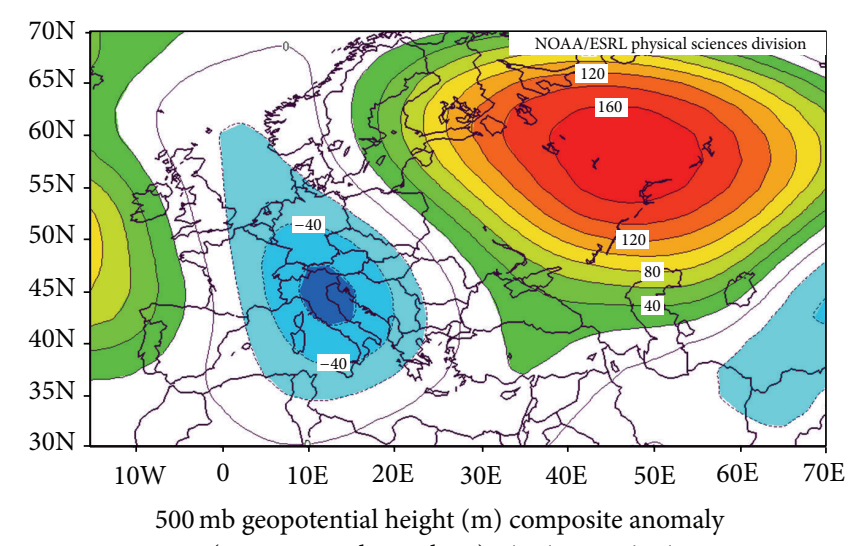
(1981-2010 climatology) $7 / 21 / 10$ to $7 / 31 / 10$ NCEP/NCAR reanalysis

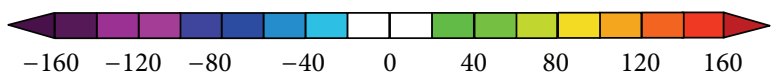

(f)

Figure 6: Continued. 

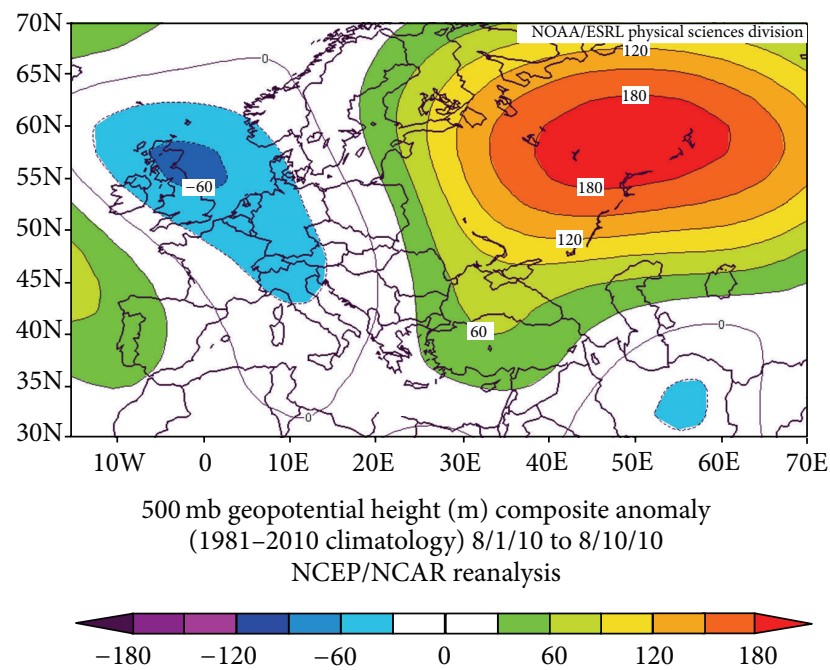

$(\mathrm{g})$

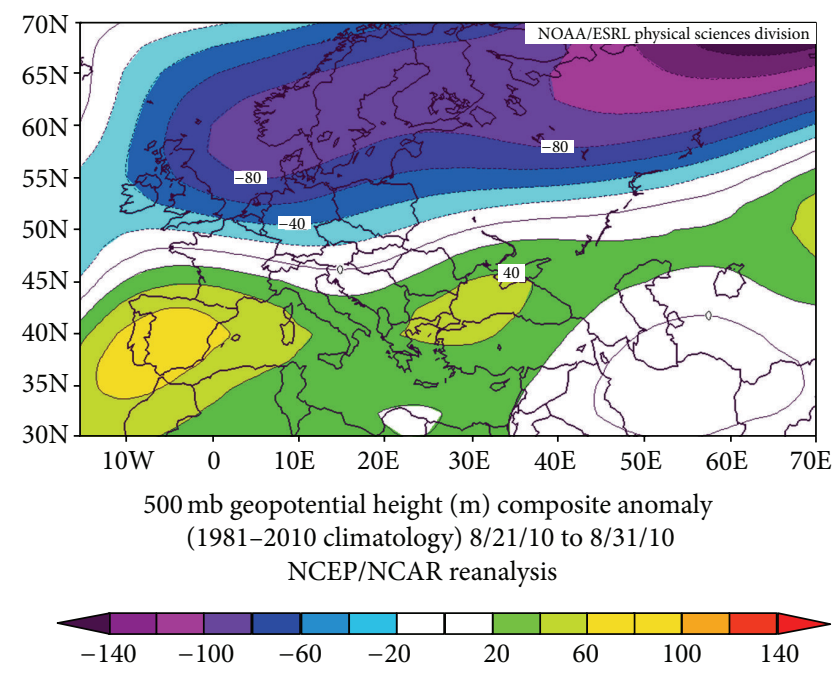

(i)

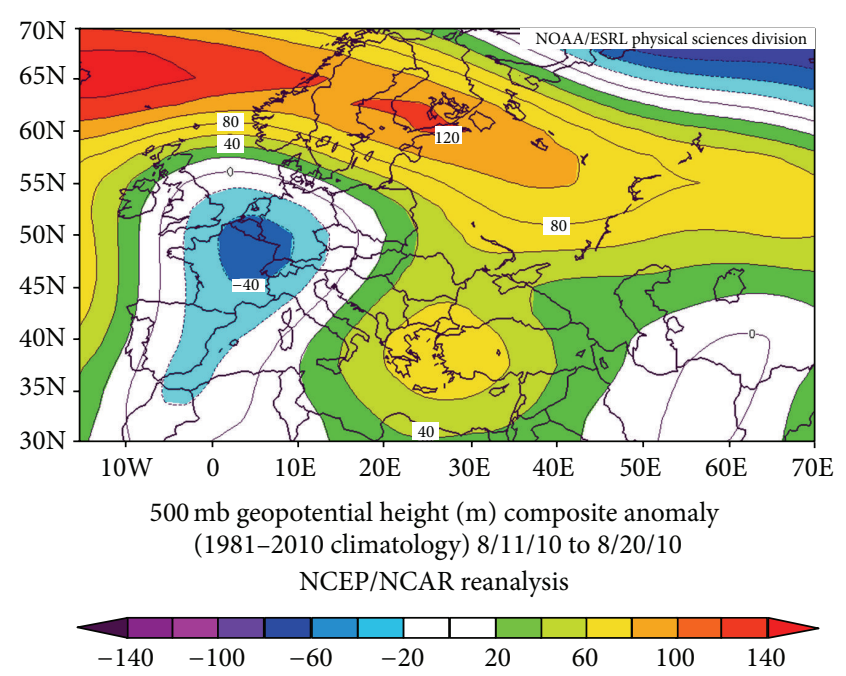

(h)

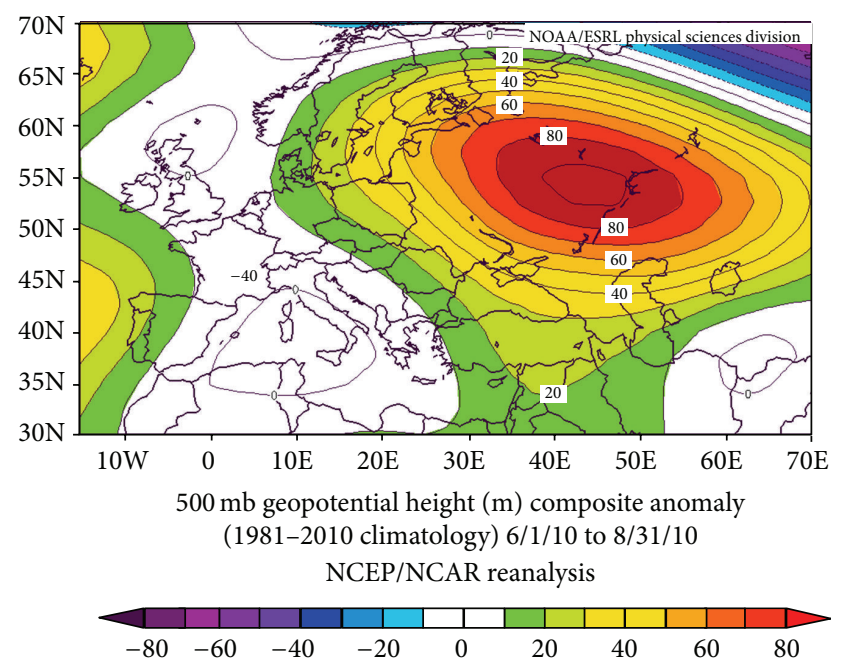

(j)

FIGURE 6: The 10 day anomaly composite mean of geopotential height at level 500 hpa over Europe during summer season of 2010.

are positive and in the opposite direction of the El-Nino3.4 trend through the study period, see Figures (10(h), and 10(i)). Stream function over KSA varies completely following the variation of El-Nino3.4 with the same negative trend as shown in Figure 10(c). The result of correlation coefficient analysis between the above mentioned meteorological elements and El Nino3.4 shows that there is significant positive correlation coefficient $[+0.33$ and +0.62$]$ between the geopotential height aloft and mean surface pressure over KSA and El Nino3.4, respectively. Meanwhile, significant negative correlation coefficients $[-0.63$ and -0.66$]$ between the precipitation rate and surface relative humidity over KSA and El Nino3.4, respectively.

\section{Discussion and Conclusion}

The above mentioned studies concerned with the variability of geopotential height anomaly at level 500 hpa over Europe, variability of climatic indices NAO, SOI, and El Nino3.4 and variability of meteorological elements over KSA for two periods. The first period is of 1948-2012 for summer seasons (June, July, and August). The second period is for the summer season of 2010. To challenge the aim of the present work, the following studies have been done. (1) Anomalies in geopotential height over Europe during summer seasons through the period 1948-2012. (2) Anomalies in weather elements over KSA in summer seasons through the period of 1948-2012. (3) Correlation coefficient analysis of anomalies in weather elements over KSA and climatic indices NAO, SOI, and El Nino3.4 in summer seasons of the period 1948-2012. (4) Blocking system over Europe in summer 2010. (5) The role played by blocking system over Europe and abnormal weather over KSA in summer 2010. (6) The relationship between climatic indices NAO index, SOI, and El-Nino3.4 and abnormal weather over KSA in summer 


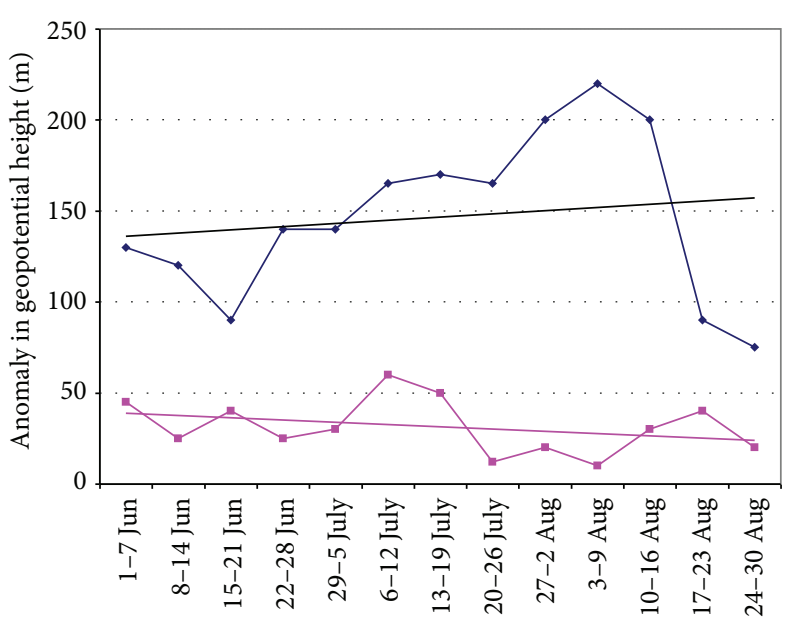

Time interval

(a)

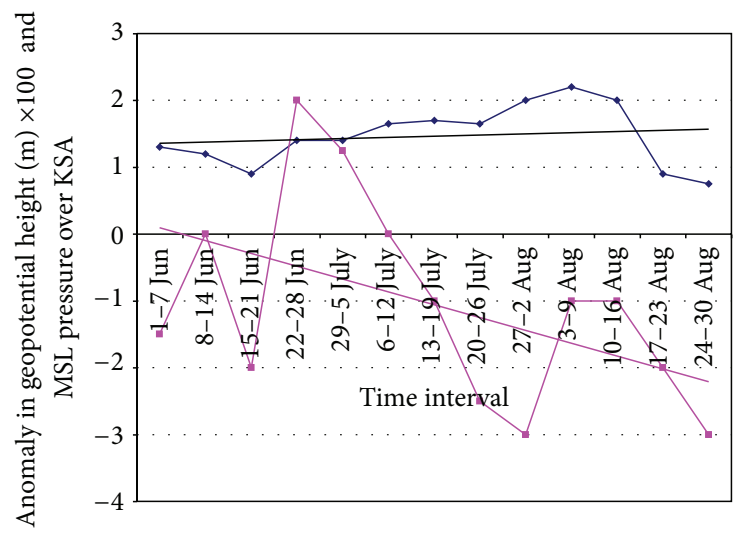

(c)

$$
\text { चี }
$$

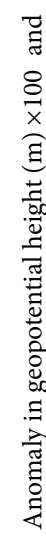

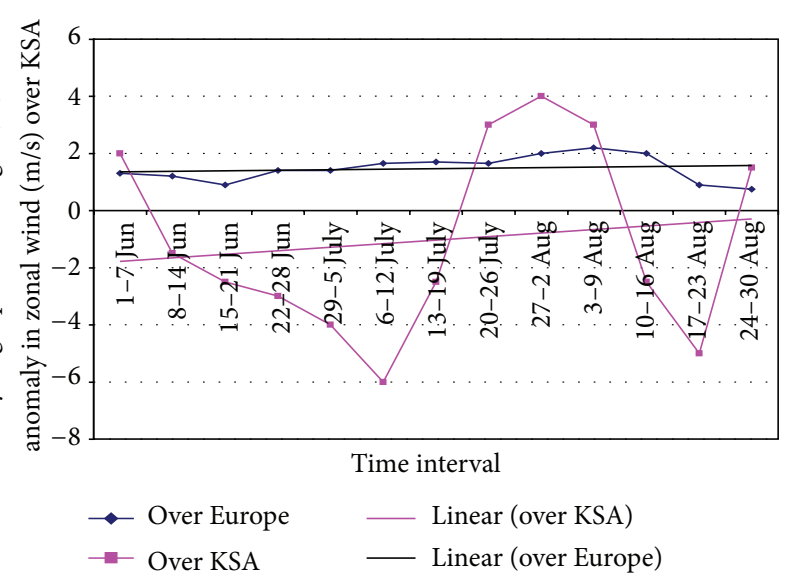

(e)

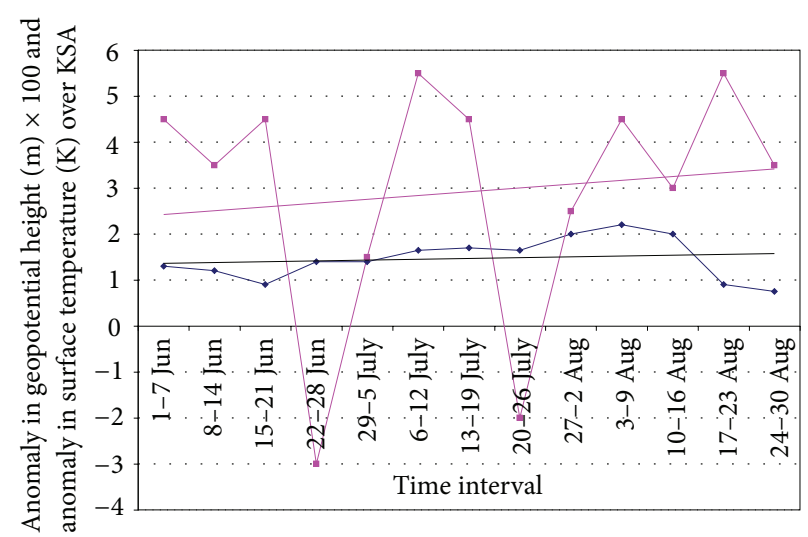

(b)

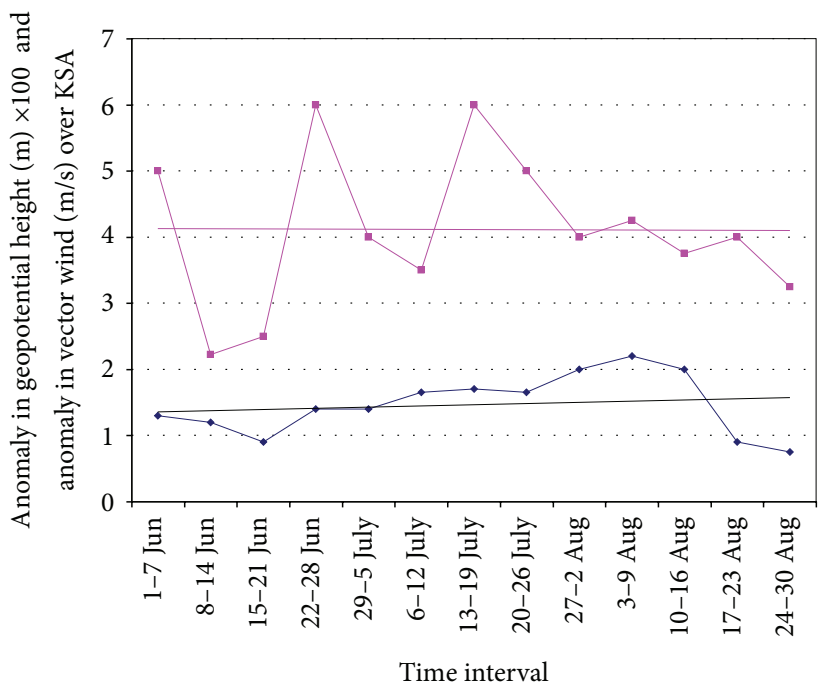

(d)

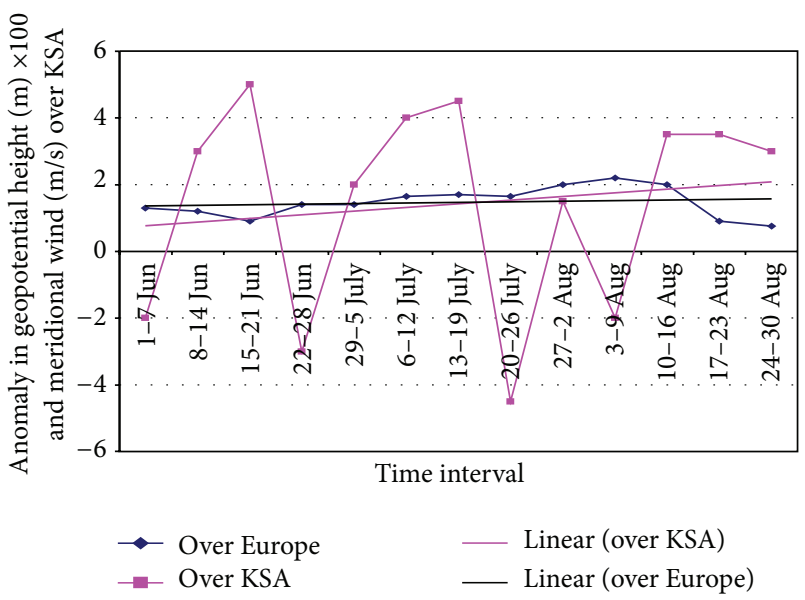

(f)

Figure 7: Continued. 


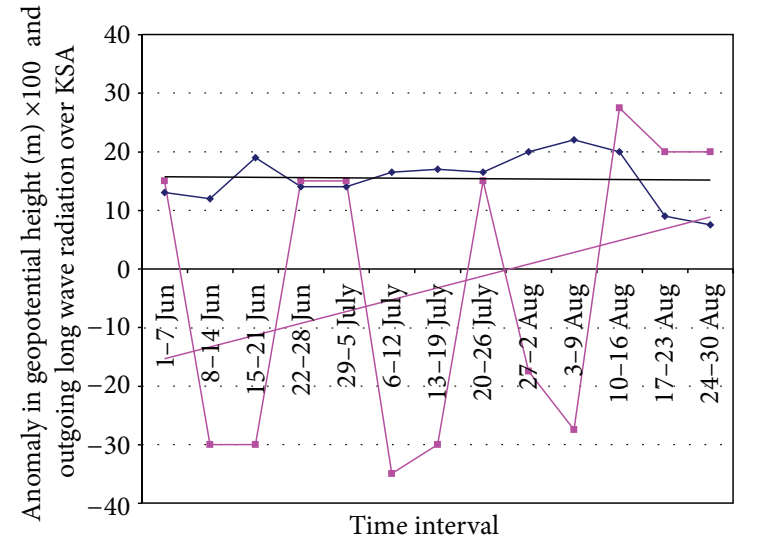

(g)

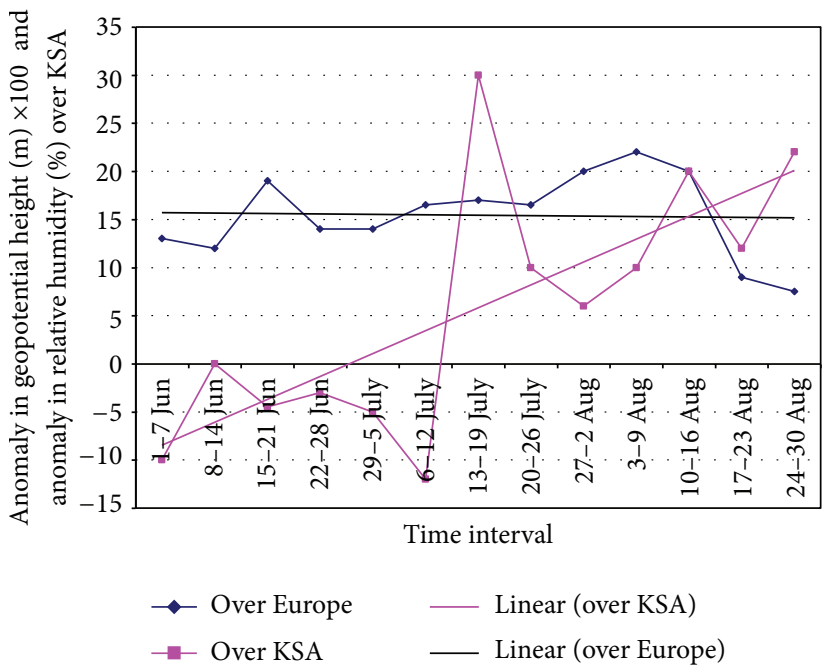

(i)

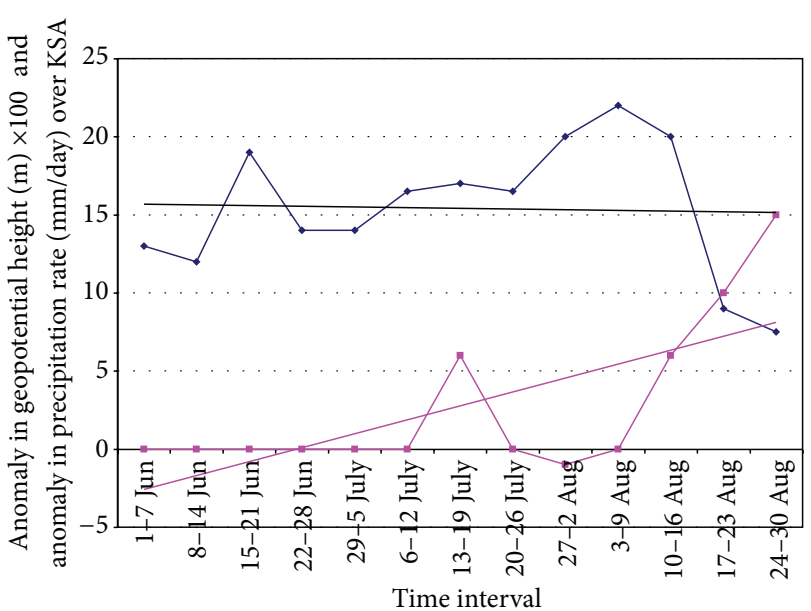

(h)

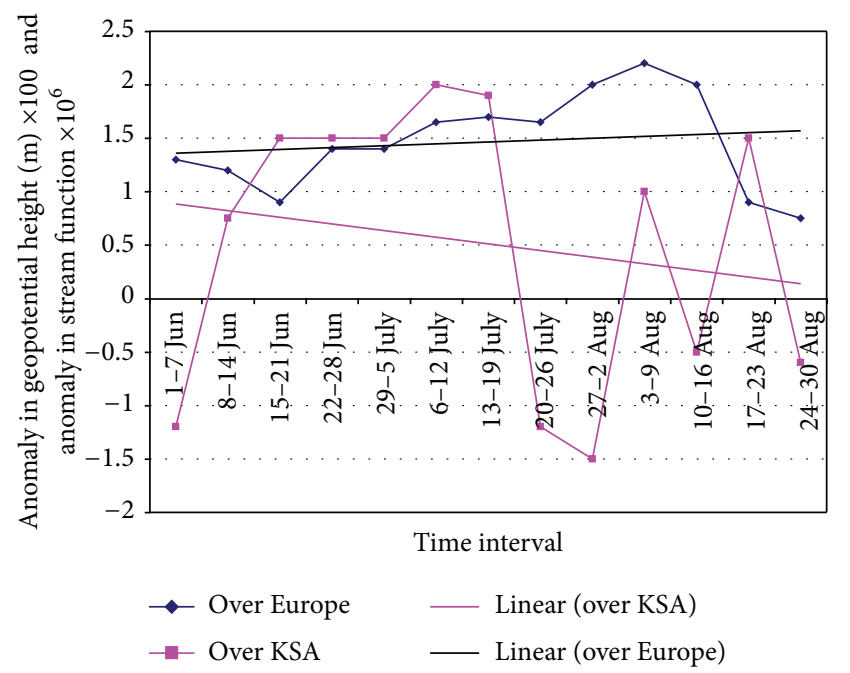

(j)

Figure 7: Time series analysis—7 days—of anomaly in geopotential height over Europe and anomaly of weather elements over KSA during the summer season 2010 .

2010. The following is clear from the above mentioned studies.

(1) There is a positive trend of geopotential height anomalies at $500 \mathrm{hpa}$ for June, July, August months and sum mer season over Europe. Also, a significant increase of geopotential height values after 2000 has been noticed for June, July, August and summer season through the period 1948-2012.

(2) There is a positive trend of weather elements over KSA (surface air temperature, geopotential height, zonal momentum flux at the surface, sea level pressure, and outgoing radiation) during June, July, August months, and summer seasons of the period of study 1948-2012. This trend is completely mentioned as the geopotential height trends that existed over Europe through that period. Meanwhile, there is negative trend of weather delements (meridional momentum flux at the surface, relative humidity, and precipitation rate) over KSA. In addition to that, surface air temperature over KSA increase gradually through the period 1948-2012 and became above its normal values for June, July, August months, and summer season from 1995 till 2012. In the same manner, geopotential height increased sharply from 1948 to 2012 and became more than its normal values after 1996 for June, July, and summer season. Meanwhile, for July it became around its normal values. Precipitation rate and humidity sharply decrease through the period 1948-2012 and became less than their normal values after the year 2000. The outgoing long wave radiation increased gradually and became more than its normal values after the year 2000. This result insured that a climatic change occurred over Europe and KSA after the year 1995. 


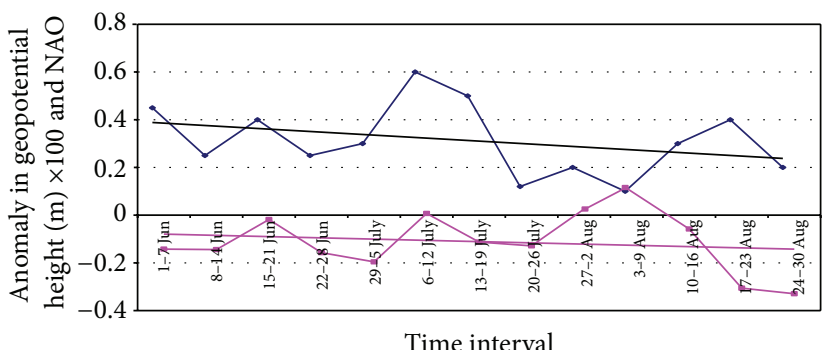

(a)

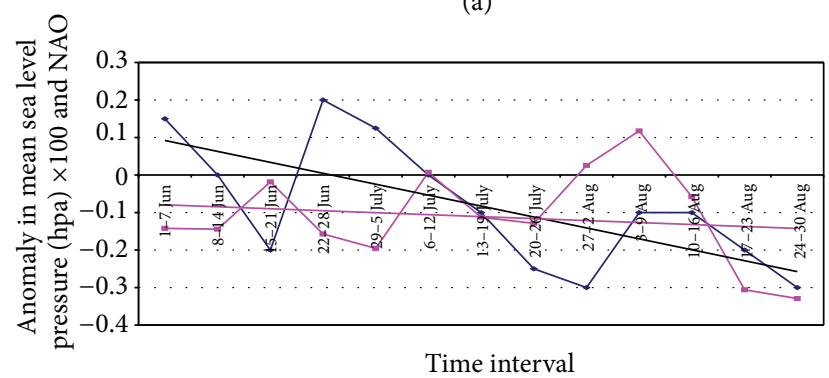

(c)

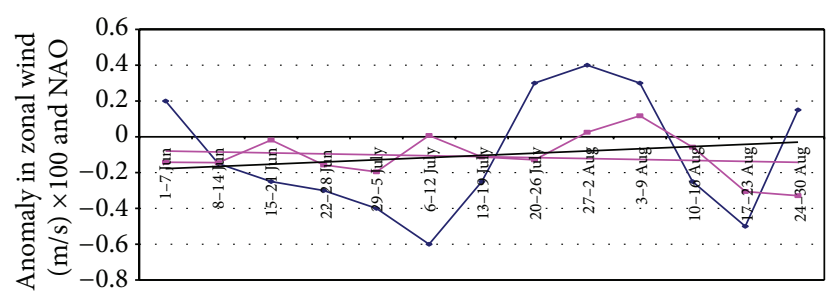

Time interval

(e)

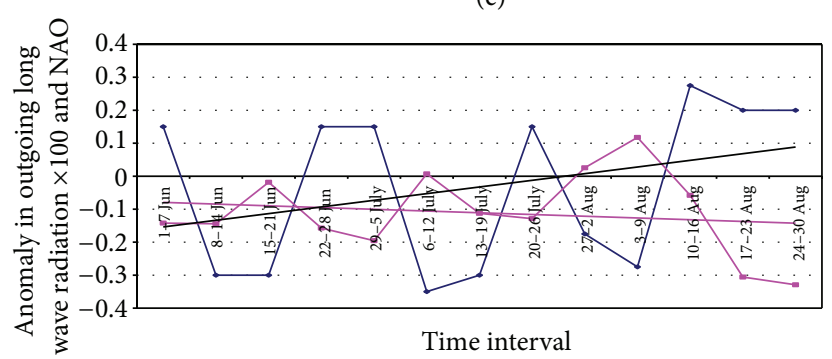

(g)

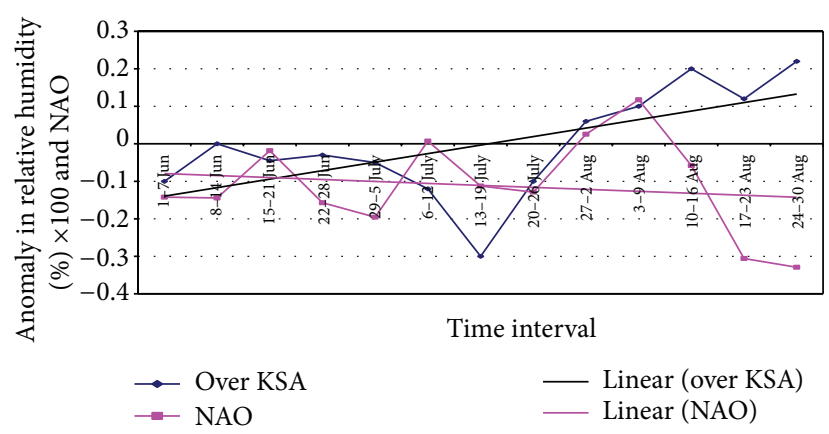

(i)

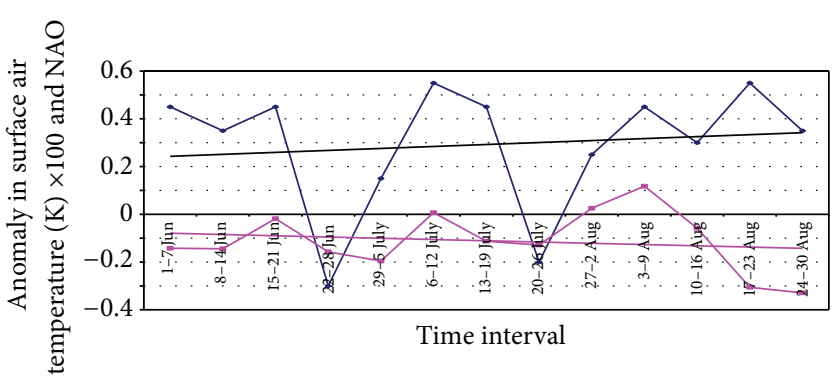

(b)

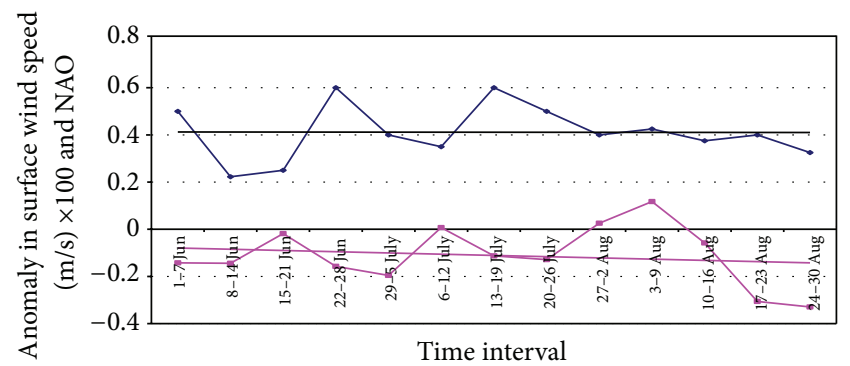

(d)

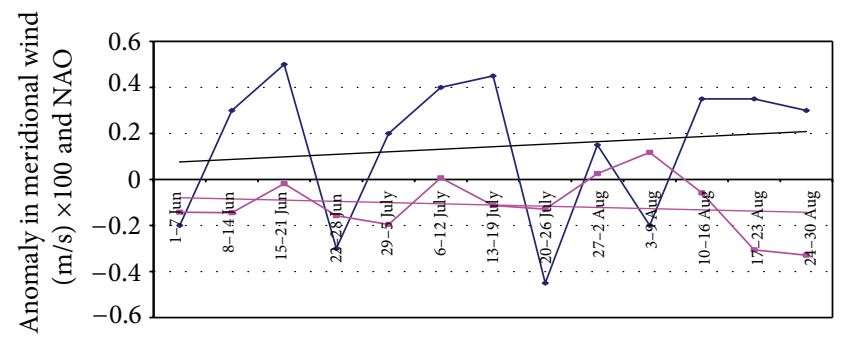

Time interval

(f)

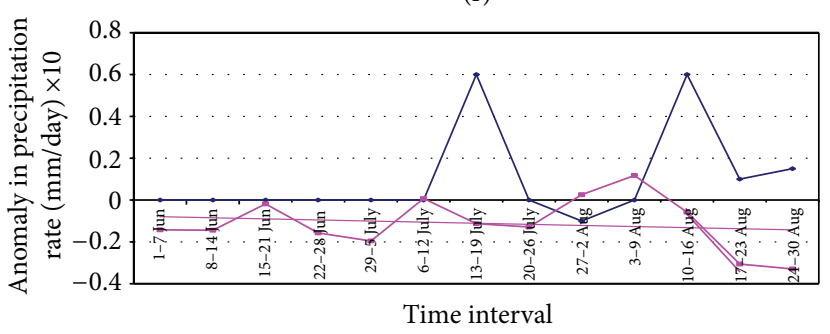

(h)

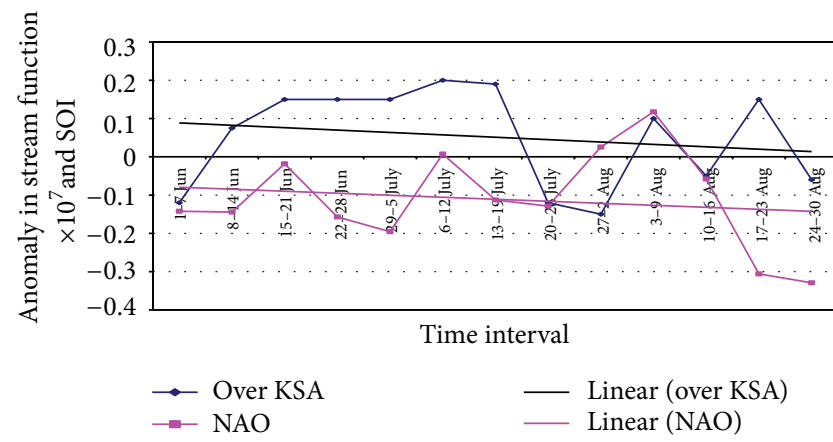

(j)

FIGURE 8: Time series analysis—7 days—of anomaly of NAO and anomaly of weather elements over KSA during the summer season 2010. 


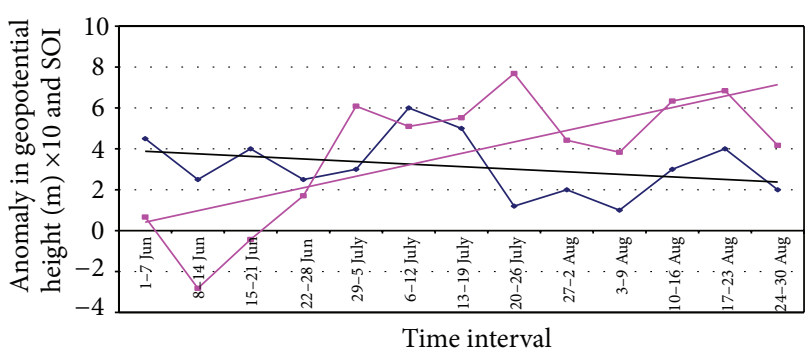

(a)

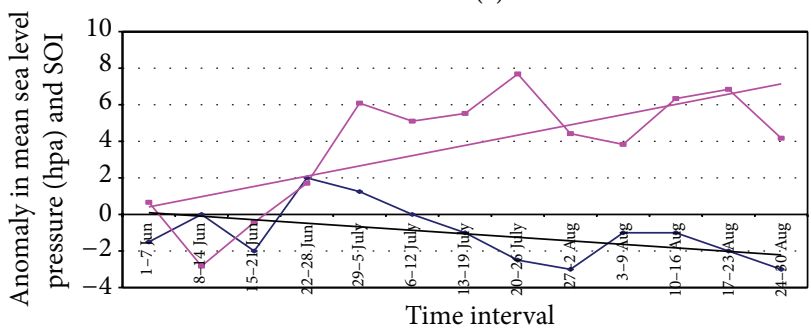

(c)

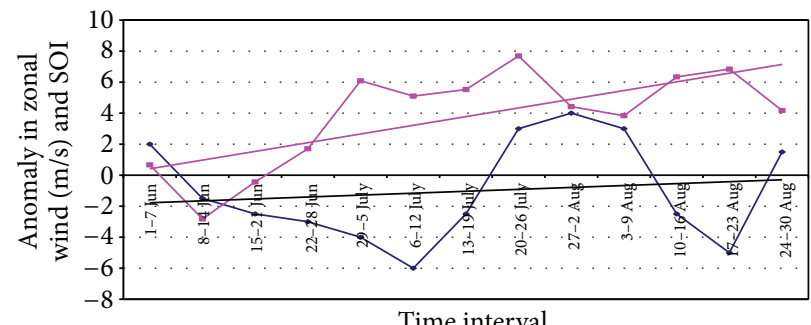

(e)

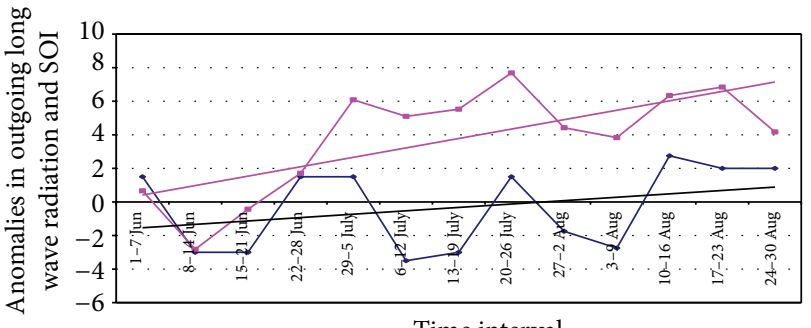

Time interval

(g)

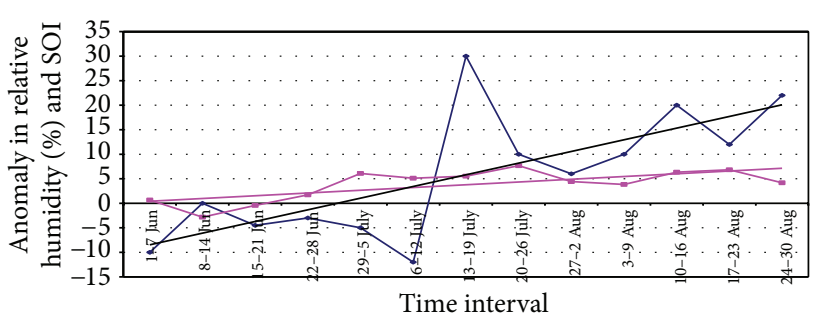

$\begin{array}{ll}\longrightarrow \text { Over KSA } & \longrightarrow \text { Linear (over KSA) } \\ \rightarrow-\text { SOI } & \text { Linear (SOI) }\end{array}$

(i)

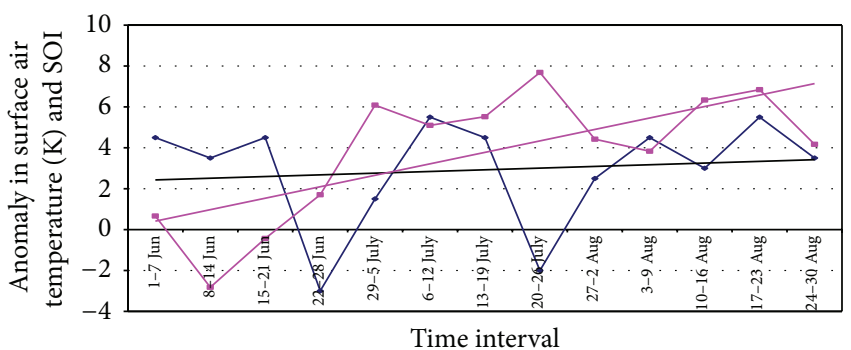

(b)

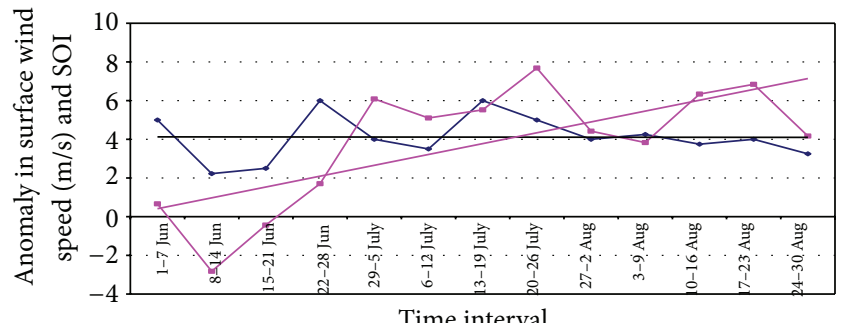

(d)

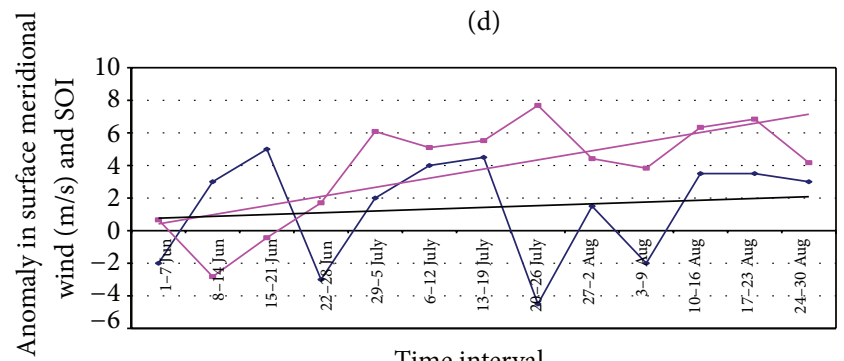

(f)

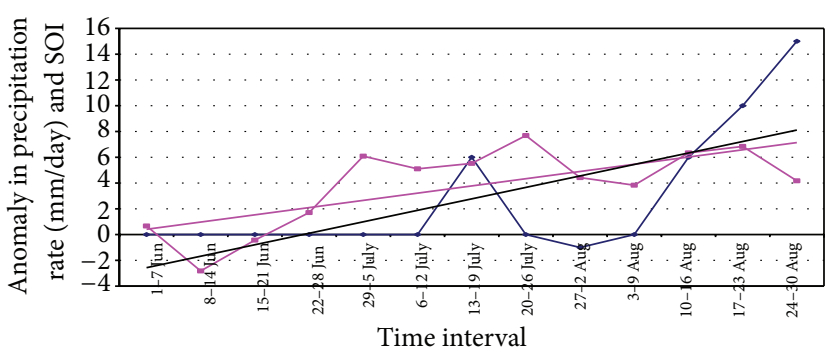

(h)

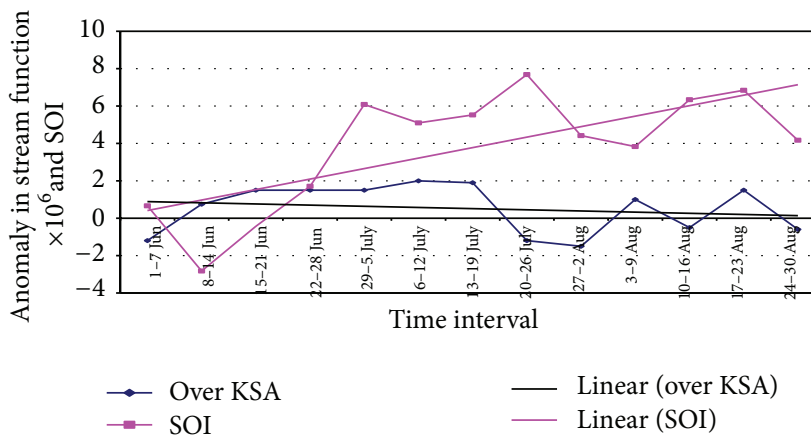

(j)

FIGURE 9: Time series analysis—7 days—of anomaly of the SOI and anomaly of weather elements over KSA during the summer season 2010. 


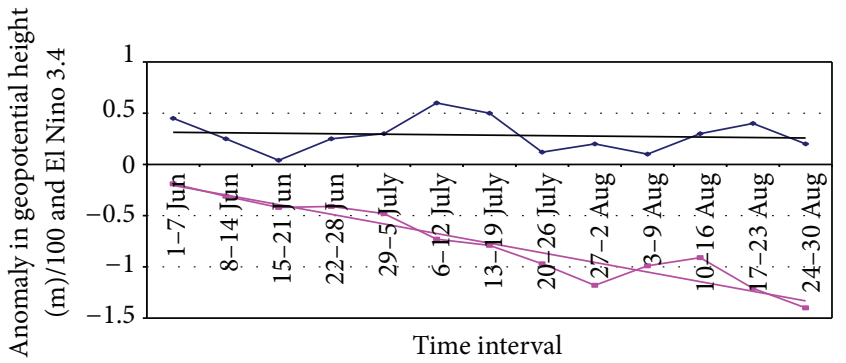

(a)

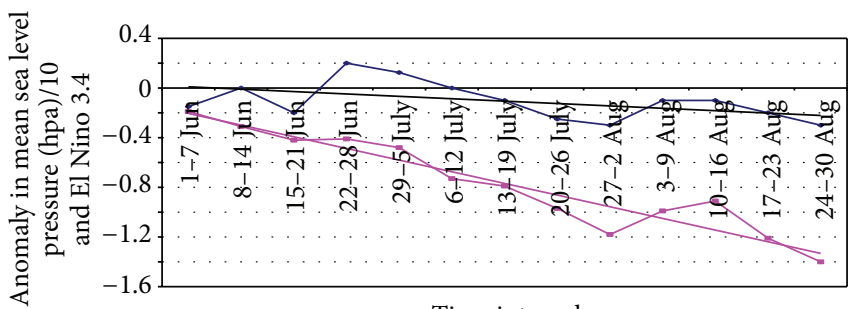

Time interval

(c)

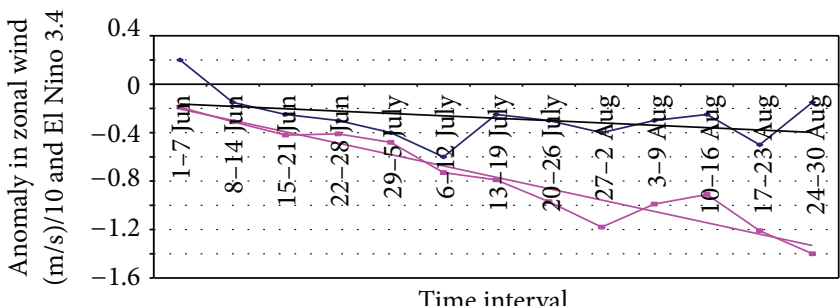

Time interval

(e)

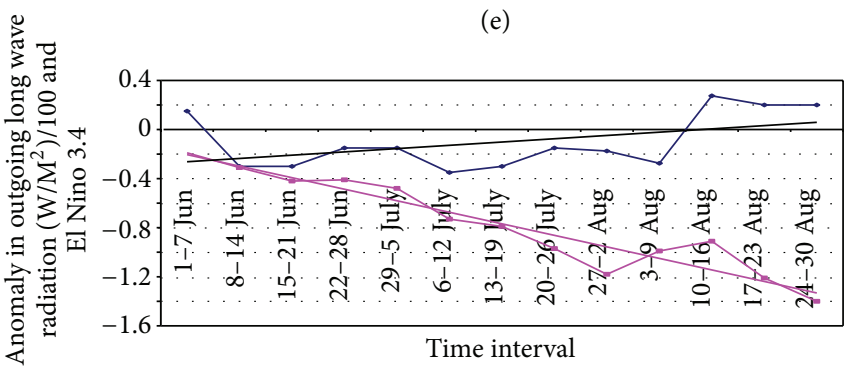

(g)

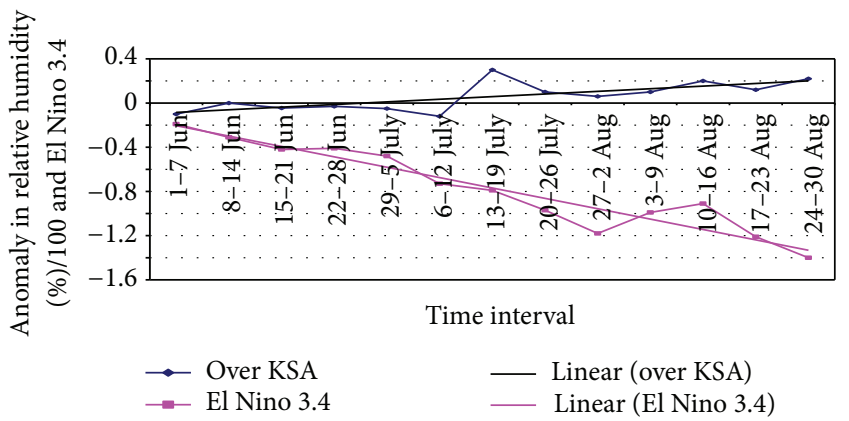

(i)

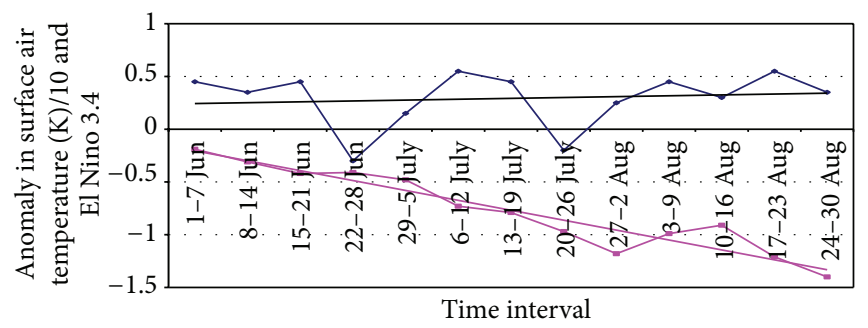

(b)

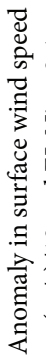

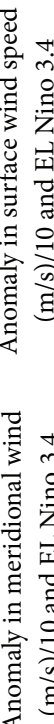

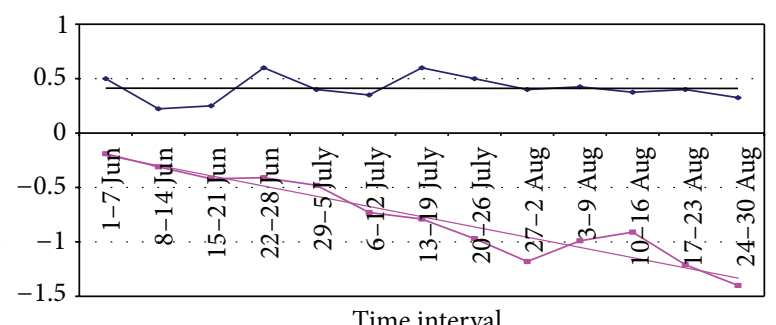

(d)
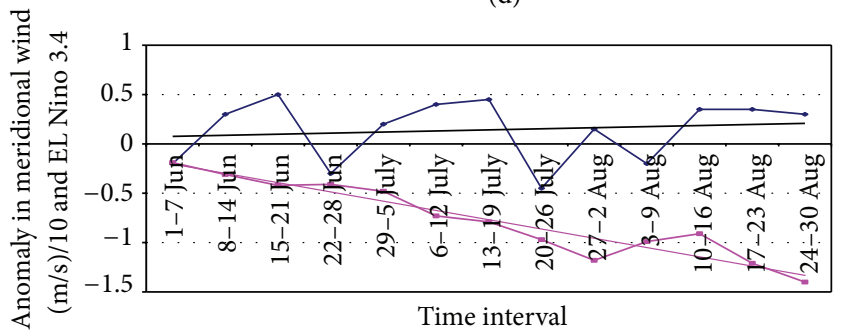

(f)

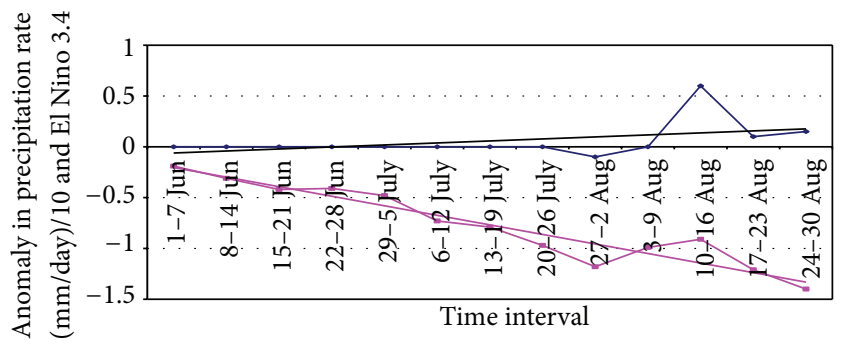

(h)

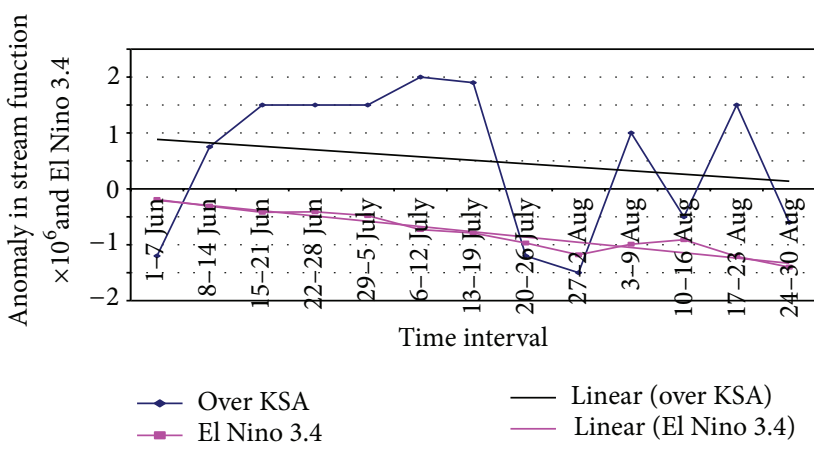

(j)

Figure 10: Time series analysis-7 days-of anomaly of the El-Nino3.4 and anomaly of weather elements over KSA during the summer season 2010. 
(3) The correlation coefficient analysis shows that there is a relatively significant negative correlation between surface air temperature over KSA and NAO through the period 1948-2012. Meanwhile, there exists a positive significant correlation between precipitation over KSA and NAO through the period 1979-2011. Sigma stream function and geopotential height have a weak correlation with NAO through the study period 19482012.

(4) There is a significant negative correlation between precipitation over KSA and SOI through the period 1979-2011. Meanwhile, there exists a weak correlation between surface air temperature over KSA and SOI. Meanwhile, for Sigma stream function and geopotential height there existed a weak correlation with SOI through the period 1948-2012.

(5) It is found that there is a significant positive correlation between geopotential height over KSA and El Nino3.4 through the period 1948-2012. Meanwhile, there exists a weak correlation between surface air temperature and sigma stream function over KSA and El Nino3.4. Precipitation in KSA has a relatively significant positive correlation coefficient with El Nino3.4.

(6) It appears that there is a unique summer geopotential height distribution over Europe in summer season 2010, whereas this season has a blocking episode over the northern hemisphere and it persists mainly over Russia for a long time reached at the time of this season. Through the persistence of this blocking system, weather over Europe and several countries in the northern hemisphere becomes an extreme, abnormal weather. KSA suffered from heat waves and abnormal weather conditions, whereas the temperature levels reached their maximum abnormal values over KSA through that season.

(7) During the period of blocking persistent over Europe in summer of 2010, time series analysis of variability of geopotential height over Europe and weather elements over KSA (geopotential height, surface air temperature, mean sea level pressure, vector wind, zonal wind, meridional wind, out long radiation, precipitation rate, relative humidity, and stream function at the surface) has been done. It is clear that there is a positive trend of surface air temperature, zonal wind, meridional wind, out long radiation, and relative humidity over KSA within the positive trend of geopotential height over Europe through the period 1 June-31 August of the year 2010. Meanwhile, geopotential height, mean sea level pressure, and stream function has a negative trend contradicting to the geopotential height trend over Europe through that period. The result of correlation coefficient analysis between the above mentioned meteorological elements and blocking over Europe (as represented by anomaly in geopotential height at $500 \mathrm{hpa}$ level over Europe) shows that there exists only a good correlation between the wind speed, zonal wind, and precipitation rate over KSA and the blocking over Europe. This block increases the stability of weather conditions and generates heat waves over KSA. This result encourages that weather of KSA through summer of year 2010 has been partially controlled by the persistence of blocking system over Europe.

(8) It is revealed that the NAO index values are less than their normal values for most of the period (1 June31 August) in year 2010 and have a negative trend. It is clear that weather elements (geopotential height, sea level pressure, and steam function) have the same negative trend of the NAO. Meanwhile, all the other weather elements have a positive trend against of NAO trend direction. The correlation coefficient analysis between the above mentioned meteorological elements and NAO shows that there only exists a significant negative correlation coefficient $[-0.63$ and -0.66] between (the outgoing long wave radiation and precipitation rate over $\mathrm{KSA}$ ) and $\mathrm{NAO}$, respectively. So, it is clear that the NAO has been controlling the weather region over KSA through that summer season.

(9) It is uncovered that almost of the period of summer 2010, SOI has a positive anomaly value and has an outstanding positive trend in contradicting NAO trend. Study of variability of SOI and the above mentioned meteorological elements over KSA has done. It is clear that weather elements (surface air temperature, zonal and meridional wind, out long wave radiation, precipitation, and relative humidity) have the same positive trend of SOI. Meanwhile, geopotential height, sea level pressure, and stream function have a negative trend against SOI trend direction. The result of correlation coefficient analysis between the meteorological elements over KSA and SOI revealed that there is only a positive correlation coefficient $[+0.38,+0.39,+0.33$ and +0.45$]$ between the surface wind speed, outgoing long wave radiation, precipitation rate, and relative humidity over KSA and SOI, respectively. It is obvious that SOI has been controlling the weather region over KSA through that summer season.

(10) It is noticed that during the period of summer 2010, El Nino3.4 has a negative anomaly value and has an outstanding negative trend in contradicting to SOI trend. Study of variability of El Nino3.4 and the meteorological elements over KSA has done. It is clear that weather elements (geopotential height, sea level pressure, and stream function) have the same negative trend of El Nino3.4. Meanwhile, surface air temperature, zonal and meridional wind, out longwave radiation, precipitation, and relative humidity have a positive trend against of El Nino3.4 trend direction. The result of correlation coefficient analysis between the above mentioned meteorological elements and El Nino3.4 shows that there is a significant positive correlation coefficient $[+0.33$ and +0.62$]$ between the 
geopotential height aloft and mean surface pressure over KSA and El Nino3.4, respectively. Meanwhile, there is a significant negative correlation coefficient $[-0.63$ and -0.66$]$ between (the precipitation rate and surface relative humidity over KSA) and El Nino3.4 respectively. This leads to say that El Nino3.4 controlled weather conditions in KSA during that summer season.

(11) In general, the present studies uncover the climatic relationship between the anomalies in geopotential height over Europe and weather conditions over KSA. The results revealed that air current aloft in the upper atmosphere over Europe, blocking systems, and climatic indices (NAO, SOI and El Nino3.4) have played a great role to impact full control of the weather conditions over KSA through the study period 1948-2012. It is clear that there is an extremely high recorded positive value of geopotential height at $500 \mathrm{hpa}$ level recorded not only over Europe but also over KSA during summer season of the year in 2010. However, the impacts of European-blocking system extended to several countries far from Europe, such as Pakistan [6]. The present work uncovers the relationship between the European block in summer 2010 (indicated by anomalies in geopotential height at 500 hpa over Europe) and climatic indices NAO, SOI and El Nino3.4 and weather over KSA during that season. It has become clear that during the period of blocking system over Europe in summer 2010, weather conditions in KSA were controlled by two distinct weather regimes their first one in the north (European blocking system and NAO); second one in the South (SOI and El Nino3.4). One can conclude that the abnormal weather over KSA in summer 2010 is a result of the occurrence of abnormal blocking persistence over Europe for an extreme duration. In addition to that, the abnormal anomaly values existed in the climatic indices NAO, SOI, and El Nino3.4 in summer 2010.

\section{Acknowledgments}

It is a pleasure to the authors to thank the Earth System Research Laboratory, Physical Sciences Division, Climate Diagnostics Centre, for supporting the data used throughout this study. Plots and images were provided by the NOAA-CIRES Climate Diagnostics Centre, Boulder, Colorado, USA from their website http://www.esrl.noaa.gov/psd/. The authors also, thank the Climate Prediction Centre for supporting the NAO, SOI, and El Nino3.4 data which were obtained through the website http://www.cpc.ncep.noaa.gov/.

\section{References}

[1] ClimateSignals report, 2010, http://climatesignals.org/2010/11/ 2010-records-most-national-extreme-heat-records-ever/heatrecords2010/.
[2] J. Blunden, D. S. Arndt, and M. O. Baringer, "State of the climate in 2010," Bulletin of the American Meteorological Society, vol. 92, pp. S1-S266, 2011.

[3] A. Schneidereit, S. Schubert, P. Vargin et al., "Large-scale flow and the long-lasting blocking high over Russia: summer 2010," Monthly Weather Review, vol. 140, pp. 2967-2981, 2012.

[4] ECMWF, “Newsletter No. 125-Autumn 2010," 2010.

[5] C. C. Hong, H. H. Hsu, N. H. Lin, and H. Chiu, "Roles of European blocking and tropical-extratropical interaction in the 2010 Pakistan flooding," Geophysical Research Letters, vol. 38, no. 13, Article ID L13806, 2011.

[6] P. J. Webster, V. E. Toma, and H.-M. Kim, "Were the 2010 Pakistan floods predictable?” Geophysical Research Letters, vol. 38, no. 4, Article ID L04806, 2011.

[7] NOAA/National Climatic Data Center, "State of the climate, global analysis for June 2010," 2010, http://www.ncdc.noaa.gov/ sotc/global/2010/6.

[8] R. H. Grumm, "The central European and Russian heat event of July-August 2010," Bulletin of the American Meteorological Society, vol. 92, pp. 1285-1296, 2011.

[9] D. Barriopedro, E. M. Fischer, J. Luterbacher, R. M. Trigo, and R. García-Herrera, "The hot summer of 2010: redrawing the temperature record map of Europe," Science, vol. 332, no. 6026, pp. 220-224, 2011.

[10] R. D. Elliott and T. B. Smith, "A study of the effects of large blocking highs on the general circulation in the NorthernHemisphere westerlies," Journal of Meteorology, vol. 6, no. 2, pp. 67-85, 1949.

[11] D. F. Rex, "The effect of Atlantic blocking action upon European climate," Tellus, vol. 3, pp. 100-111, 1951.

[12] J. Namias, "Seasonal persistence and recurrence of European blocking during 1958-1960," Tellus, vol. 6, pp. 394-407, 1964.

[13] R. R. Dickson and J. Namis, "North America influences on the circulation and climate of the North Atlantic sector," Monthly Weather Review, vol. 104, pp. 1255-1265, 1976.

[14] R. M. Dole and N. D. Gordon, "Persistent anomalies of the extratropical Northern Hemisphere wintertime circulation: geographical distribution and regional persistence characteristics," Monthly Weather Review, vol. 111, no. 8, pp. 1567-1586, 1983.

[15] A. R. Lupo and P. J. Smith, "Planetary and synoptic-scale interactions during the life cycle of a mid-latitude blocking anticyclone over the North Atlantic," Tellus A, vol. 47, no. 5, pp. 575-596, 1995.

[16] H. Lejenas, "The severe winter in Europe 1941-1942: the largescale circulation, cut-off lows, and blocking," Bulletin of the American Meteorological Society, vol. 70, no. 3, pp. 271-281, 1989.

[17] J. Cohen, K. Saito, and D. Entekhabi, "The role of the Siberian High in Northern Hemisphere climate variability," Geophysical Research Letters, vol. 28, no. 2, pp. 299-302, 2001.

[18] Y. Y. Hafez, "The role played by blocking over the Northern Hemisphere on Hurricane Katrina," The Journal of American Science, vol. 4, no. 2, pp. 10-25, 2008.

[19] Y. Y. Hafez, "Relationship between geopotential height anomalies over North America and Europe and the USA landfall Atlantic hurricanes activity," The Journal of American Science, vol. 7, no. 6, pp. 663-671, 2011.

[20] Y. Y. Hafez, "Blocking systems persist over North Hemispher and its role in extreme hot waves over Russia during summer 2010," in Atmospheric Model Applications, I. Yucel, Ed., pp. 978953, InTech, 2012. 
[21] H. Athar, M. Almazroui, M. Nazrul Islam, M. Adnan Abid, and M. Azhar Ehsan, "Effect of mid-latitude blocking anticyclones on the weather of the Arabian Peninsula," International Journal of Climatology, vol. 33, no. 3, pp. 585-598, 2012.

[22] D. F. Rex, "Blocking action in the middle troposphere and its effect on regional climate I: an aerological study of blocking action," Tellus, vol. 3, pp. 196-211, 1950.

[23] R. A. Treidl, E. C. Birch, and P. Sajecki, "Blocking action in the Northern Hemisphere: a climatological study," AtmosphereOcean, vol. 19, pp. 1-23, 1981.

[24] W. B. White and N. E. Clark, "On the development of blocking ridge activity over the central North Pacific," Journal of the Atmospheric Sciences, vol. 32, no. 3, pp. 489-502, 1975.

[25] H. Lejenas and H. Okland, "Characteristics of Northern Hemisphere blocking as determined from a long time series of observational data," Tellus A, vol. 35, no. 5, pp. 350-362, 1983.

[26] S. Tibaldi and F. Molteni, "On the operational predictability of blocking," Tellus A, vol. 42, no. 3, pp. 343-365, 1990.

[27] S. Tibaldi, F. D’Andrea, E. Tosi, and E. Roeckner, "Climatology of Northern Hemisphere blocking in the ECHAM model," Climate Dynamics, vol. 13, no. 9, pp. 649-666, 1997.

[28] R. M. Trigo, I. F. Trigo, C. C. DaCamara, and T. J. Osborn, "Climate impact of the European winter blocking episodes from the NCEP/NCAR reanalyses," Climate Dynamics, vol. 23, no. 1, pp. 17-28, 2004.

[29] R. M. Dole and N. D. Gordon, "Persistent anomalies of the extratropical Northern Hemisphere wintertime circulation: geographical distribution and regional persistence characteristics," Monthly Weather Review, vol. 111, no. 8, pp. 1567-1586, 1983.

[30] J. W. Hurrell, "Decadal trends in the North Atlantic Oscillation: regional temperatures and precipitation," Science, vol. 269, no. 5224, pp. 676-679, 1995.

[31] A. Shabbar, J. Huang, and K. Higuchi, "The relationship between the wintertime North Atlantic oscillation and blocking episodes in the North Atlantic," International Journal of Climatology, vol. 21, no. 3, pp. 355-369, 2001.

[32] J. A. Renwick and J. M. Wallace, "Relationships between North Pacific wintertime blocking, El Nino, and the PNA pattern," Monthly Weather Review, vol. 124, no. 9, pp. 2071-2076, 1996.

[33] J. S. Watson and S. J. Colucci, "Evaluation of ensemble predictions of blocking in the NCEP global spectral model," Monthly Weather Review, vol. 130, no. 12, pp. 3008-3021, 2002.

[34] P. A. Stott, D. A. Stone, and M. R. Allen, "Human contribution to the European heatwave of 2003," Nature, vol. 432, no. 7017, pp. 610-614, 2004.

[35] L. Feudale and J. Shukla, "Influence of sea surface temperature on the European heat wave of 2003 summer. Part II: a modeling study," Climate Dynamics, vol. 36, no. 9, pp. 1705-1715, 2011.

[36] R. Dole, M. Hoerling, J. Perlwitz et al., "Was there a basis for anticipating the 2010 Russian heat wave?" Geophysical Research Letters, vol. 38, no. 6, 2011.

[37] IPCC (Intergovernmental Panel on Climate Change), "Climate change. The physical science basis," in Contribution of Working Group I to the Fourth Assessment Report of the Intergovernmental Panel on Climate Change, S. Solomon, D. Qin, M. Manning et al., Eds., p. 996, Cambridge University Press, New York, NY, USA, 2007.

[38] E. Kalnay, M. Kanamitsu, R. Kistler et al., "The NCEP/NCAR 40-year reanalysis project," Bulletin of the American Meteorological Society, vol. 77, no. 3, pp. 437-471, 1996.
[39] H. M. Hasanean and A. K. ALkhalaf, "Variability of wintertime surface air temperature over the Kingdom of Saudi Arabia," Atmospheric and Climate Sciences, vol. 2, pp. 307-321, 2012.

[40] K. E. Trenberth, "The definition of El Niño," Bulletin of the American Meteorological Society, vol. 78, no. 12, pp. 2771-2777, 1997.

[41] J. L. Philips, How to Think about Statistics, W.H. Freeman, New York, NY, USA, 5th edition, 1996.

[42] R. E. Livezey and W. Y. Chen, "Statistical field significance and its determination by Monte Carlo techniques," Monthly Weather Review, vol. 111, no. 1, pp. 46-59, 1983.

[43] M. R. Spiegel, Theory and Problems of Statistics, Schaum, 1961.

[44] D. F. Rex, "Blocking action in the middle troposphere and its effect on regional Climate II: the climatology of blocking action," Tellus, vol. 3, pp. 275-301, 1950. 

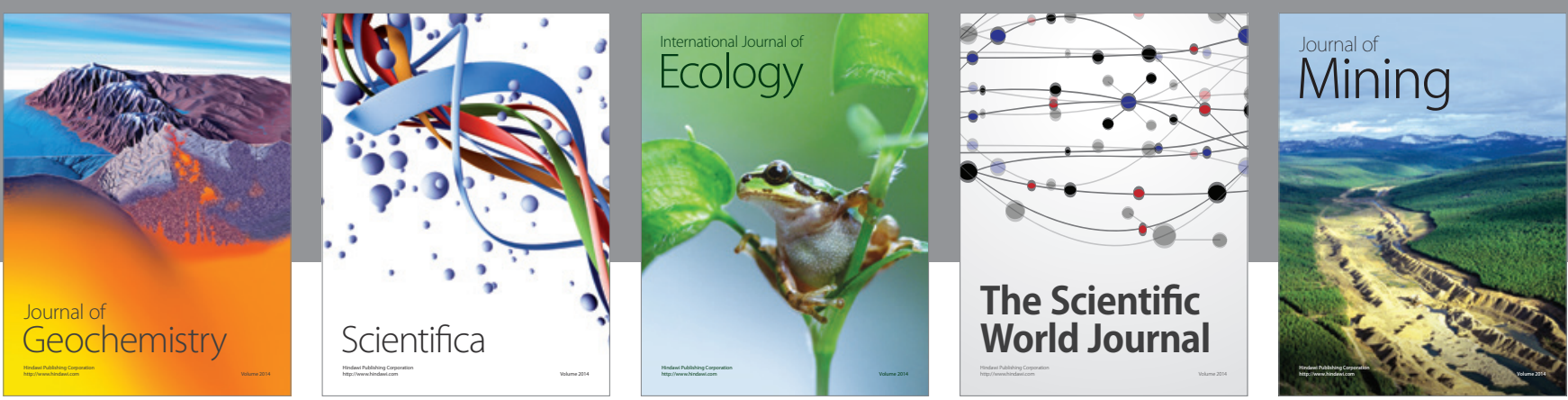

The Scientific World Journal
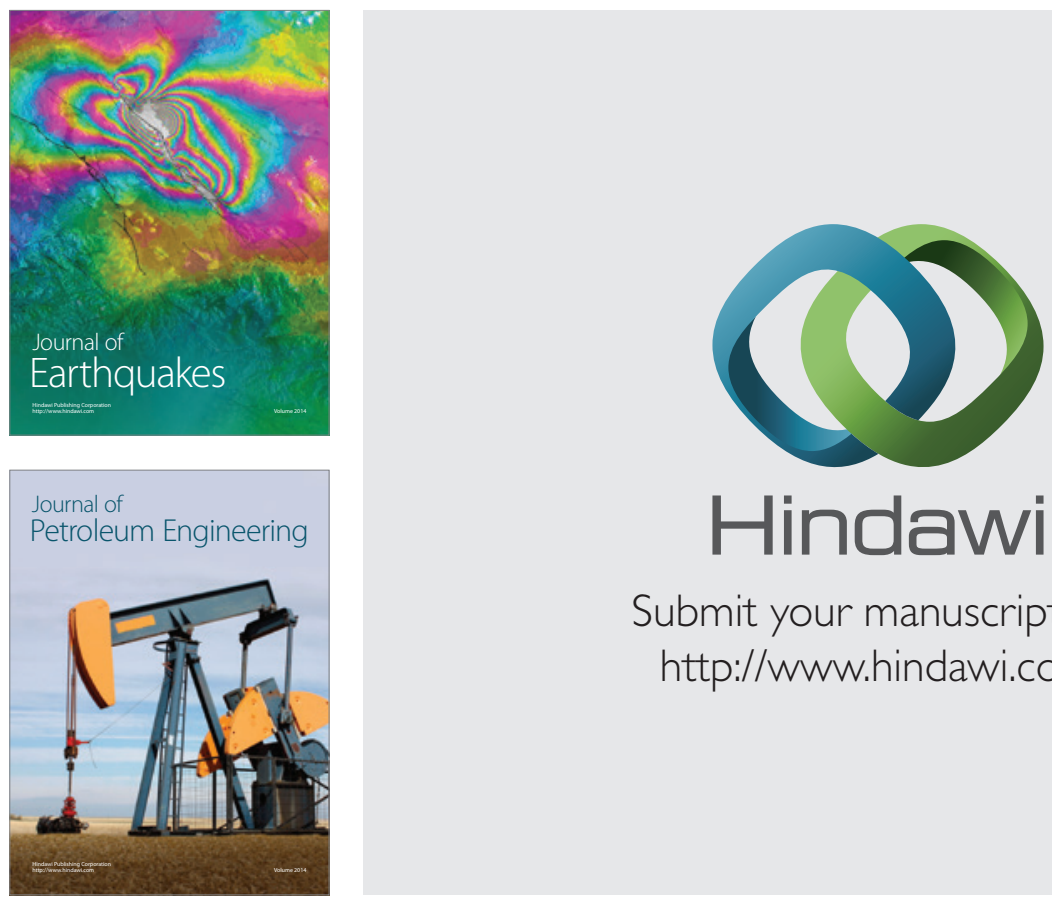

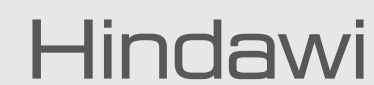

Submit your manuscripts at

http://www.hindawi.com
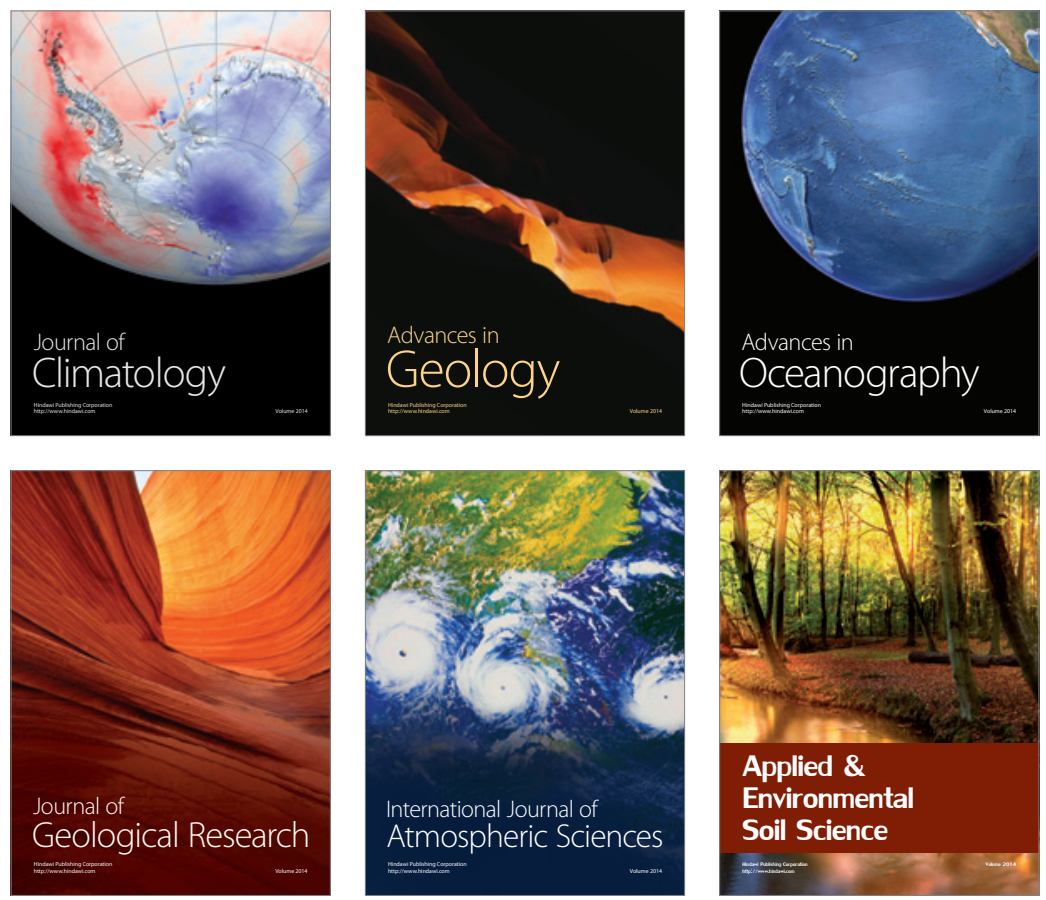
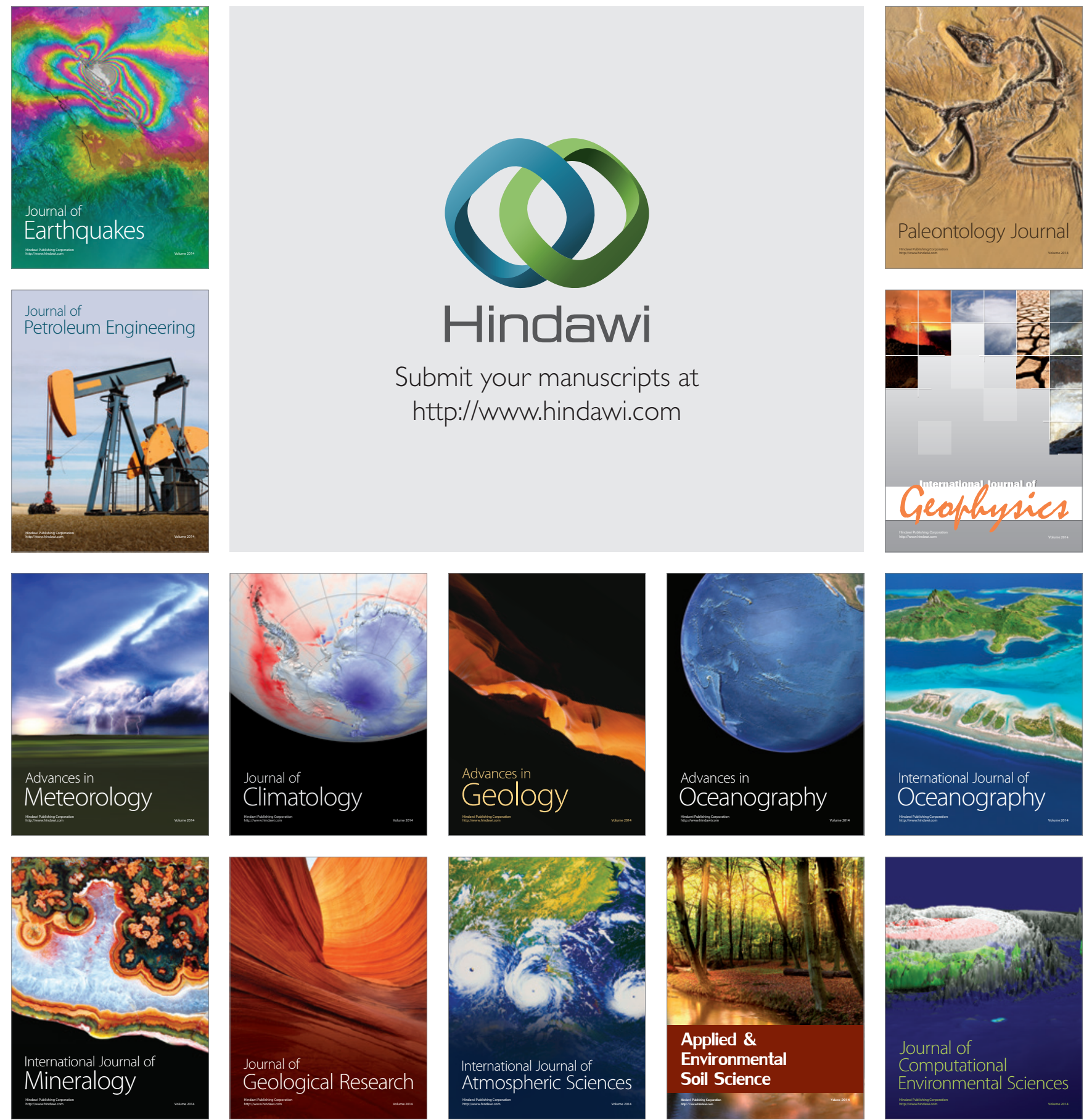